\title{
Design of Hydraulic Bulging Die for Automobile Torsion Beam and Optimization of Forming Process Parameters
}

\author{
Kefan Yang $\mathbb{D}^{\mathrm{D}}$, Youmin Wang, and Kexun Fu \\ College of Mechanical Engineering, Anhui Polytechnic University, Wuhu, Anhui 241000, China \\ Correspondence should be addressed to Kefan Yang; 2200120138@stu.ahpu.edu.cn
}

Received 29 March 2021; Accepted 3 June 2021; Published 11 June 2021

Academic Editor: Ashwini Kumar

Copyright (c) 2021 Kefan Yang et al. This is an open access article distributed under the Creative Commons Attribution License, which permits unrestricted use, distribution, and reproduction in any medium, provided the original work is properly cited.

\begin{abstract}
The hydraulic bulging technology of tubes can provide hollow parts with special-shaped cross sections. Its manufacturing process can effectively improve material utilization and product accuracy and reduce the number and cost of molds. However, the hydraulic bulging process of parts is very complicated. The size of the tube blank, the design of the loading route, and the forming process parameters will have an effect on the molding quality. Closed tubular torsion automobile beam is considered as the research object to study hydraulic bulging die design and optimize forming process parameters. CATIA software is used to design torsion beam product structure and hydraulic bulging die. AMESim software is employed to design hydraulic synchronous control system for cylinders on both sides of the hydraulic bulging die. Mathematical control model is established and verified in Simulink software. DYNAFORM software is applied to conduct numerical simulation of hydraulic expansion. The supporting pressure, molding pressure, friction coefficient, and feeding quantity are taken as orthogonal experiment level factors. Maximum thinning and maximum thickening rates are taken as hydraulic pressure expansion evaluation indexes to complete the orthogonal experiments. Main molding process parameters are analyzed via orthogonal experiment results and optimized by employing the Taguchi method. Optimal hydraulic bulging parameters are obtained as follows: supporting pressure of $20 \mathrm{MPa}$, molding pressure of $150 \mathrm{MPa}$, feeding quantity of $25 \mathrm{~mm}$, and friction coefficient of 0.075 . Simulation analysis results indicate that the maximum thinning rate is equal to $9.013 \%$, while the maximum thickening rate is equal to $16.523 \%$. Finally, the design of hydraulic bulging die for torsion beam was completed, and its forming process parameters were optimized.
\end{abstract}

\section{Introduction}

Molding plays an important role in modern machinery manufacturing industry [1]. Traditional mold design and manufacturing often rely on daily practical production experience to achieve the best effect in repeated debugging. With the development of lightweight automobiles, weight reduction of vehicle body is continuously pursued while maintaining vehicle performance. Thus, energy saving and emission reduction are achieved. This also means that traditional auto parts are transformed, while solid components with large quality and complex assembly are gradually transformed into hollow components with lightweight and integrated assembly. As a consequence, corresponding parts of product development and mold manufacturing methods are also altered. As one of new lightweight manufacturing processes, tube hydraulic bulging technology can open tube internal high-pressure liquid integral bulging to produce hollow parts with complex cross sections. This simplifies the production process and improves the product quality. Furthermore, it is a widely applied prospect in achieving lightweight construction of an automobile.

Torsion beam suspension is a type of rear suspension which is mainly used to balance the vibration of two wheels during driving. Traditional open torsion beam is made of sheet metal stamping. Its parts are high quality products while the production process itself is cumbersome. However, closed torsion beam with hydraulic expansion can be formed on the premise of ensuring the performance of parts, which reduces the number of molds and manufacturing costs.

Yin et al. [2] used finite element method to study wall thickness variation law of typical sections during tubular 
torsion forming. The results show that transition area wall thickness significantly changes during torsion beam hydraulic bulging. In addition, wall thickness variation in the middle area is not significant. Lu et al. [3] performed forward design of variable cross section hydraulic expansion type torsion beam. The authors obtained tubular torsion beam with special-shaped cross section which meets the requirements of design objectives.

Naeini et al. [4] studied and optimized pressure and force loading paths in the process of tube hydroforming via simulated annealing optimization method. Rao [5] employed Taguchi algorithm to optimize process parameters. Furthermore, the author determined optimal combination of process parameters according to the influence of tube expansion height and thinning distribution. Dhinakaran et al. [6] used CATIA to model the automotive steering knuckle and carried out stiffness analysis in OptiStruct; based on the analysis results, proposed design modifications and topology optimization were performed on the steering knuckle for lowering of the weight.

In the present study, torsion beam index parameters are designed and studied. In addition, all parameters regarding size and cross section of torsion beam studied in this paper are designed, and effects of feed quantity and friction coefficient on process parameters were further studied. Moreover, to analyze the influence degree of various factors, four-level experimental table was established by using the orthogonal experiment. In this paper, computer software CATIA is employed to design tubular torsion beam. Corresponding materials and initial tube blanks are selected for the processed products. Forming process of parts is determined, and calculation of relevant process parameters in hydraulic bulging is achieved. Hydraulic synchronous control system for automatic deviation correction is designed for synchronous cylinders on both mold sides. Synchronous displacement curves of two cylinder piston rods under two different operating conditions are obtained in AMESim. In addition, automatic hydraulic control system deviation correction function is successfully verified. Mathematical model of synchronous control system is established, and transfer function of a closed-loop control system is derived. Step response curve of the system is obtained via Simulink. Taking maximum thinning and maximum thickening rates of part's wall thickness as forming evaluation indexes, hydraulic bulging process simulation analysis of torsion beam is completed in DYNAFORM. Taguchi algorithm is employed to optimize process parameters of hydraulic bulging torsion beam. Finally, the accuracy of optimization results is verified via DYNAFORM.

\section{Automobile Tubular Torsion Beam Structure Design}

CATIA is used to carry out three-dimensional modeling design for the closed tubular torsion beam. Basic dimensions are as follows: the length is $1260 \mathrm{~mm}$, the maximum height difference between two part ends is $85.2 \mathrm{~mm}$, the surface area is $0.356 \mathrm{~m}^{2}$, and the basic wall thickness is $3 \mathrm{~mm}$. This part is symmetrical from left to right, as shown in Figure 1.
The left half of the torsion beam is selected for analysis. Left side of section B-B is the port area, whose shape remains unchanged. Cross section B-B to cross section E-E is defined as the transition zone with complex and variable cross sections. Sections E-E and F-F are V-shaped with unaltered cross section areas, as shown in Figure 2.

Perimeter of each torsion beam characteristic section is shown in Table 1. Minimum transversal fillet radius of $5 \mathrm{~mm}$ on the outer surface of the torsion beam appears in the F-F section. Outer edge transversal perimeter value is equal to a minimum of $330.48 \mathrm{~mm}$ at section $\mathrm{D}-\mathrm{D}$ and a maximum of $365.13 \mathrm{~mm}$ at section B-B.

According to Figure 2, minimum torsion beam section circumference is $330.48 \mathrm{~mm}$. Selected pipe diameter must be lower than the minimum section circumference of the torsion beam. Therefore, according to the requirements of forming and convenient pipe fitting procurement, the initial diameter of the transverse pipe is proposed as $\varnothing 104 \mathrm{~mm}$ with the corresponding wall thickness of $3 \mathrm{~mm}$.

Length of pipe fittings is related to automobile torsion beam part size and ductility of pipe fittings. The length of the torsion beam is $1260 \mathrm{~mm}$. To ensure material filling at both ends and fully formed party without causing excessive material waste, preliminary length of beam pipe fittings is $1290 \mathrm{~mm}$. Therefore, the tube blank size is defined as $\varnothing 104 \mathrm{~mm} \times 1290 \mathrm{~mm} \times 3 \mathrm{~mm}$.

\section{Automobile Torsion Beam Hydraulic Bulging Die Design}

3.1. Design of Hydraulic Bulging Die for Torsion Beam. Hydraulic bulging mold is mainly composed of an upper die and lower die bases, punch, matrix, left and right axial sealing plugs, positioning plates, guide columns, and guide sleeves. In Figure 3, assembly effect drawing is shown. Since there is currently no relevant standard for pipe fitting hydraulic forming die design, only standard design of traditional liquid bulging forming process die is employed in this paper. Thus, hydraulic pressure and tightness are considered when designing the hydraulic bulging die.

Parting surface selection should respect certain requirements. The parting surface should be selected at the largest part contour. Otherwise, the torsion beam cannot be removed from the cavity [7]. Precision requirements are higher for the transition zone of hydraulic expansion type torsion beam. Dimensional accuracy of parts is affected by the internal pressure, while selection of parting surface is also convenient for mold processing and manufacturing. According to these requirements, the parting line is opened on both sides of the widest side of the torsion beam surface, as shown in Figure 4, with a horizontal height of $62 \mathrm{~mm}$ from the bottom of the matrix.

Both punch and matrix of this design adopt the inlay manufacturing process, as shown in Figure 5. According to the role of different mold design and manufacture inserts, while taking into account wear resistance and strength of each part, manufacturing quality and efficiency of parts are improved. When processing other hydraulic bulging products, the insert can be replaced accordingly. 


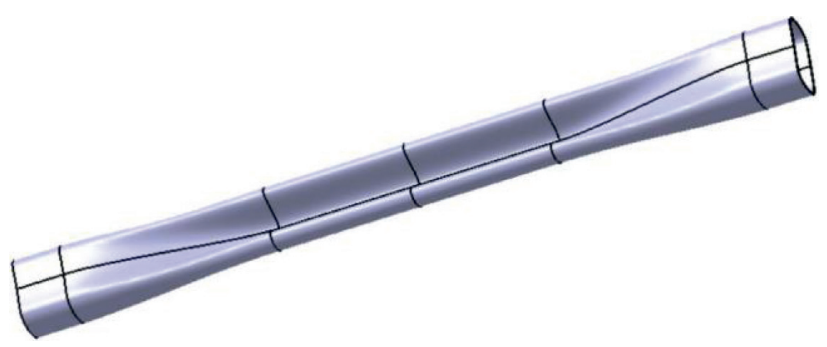

Figure 1: Original mathematical model diagram of the torsion beam.
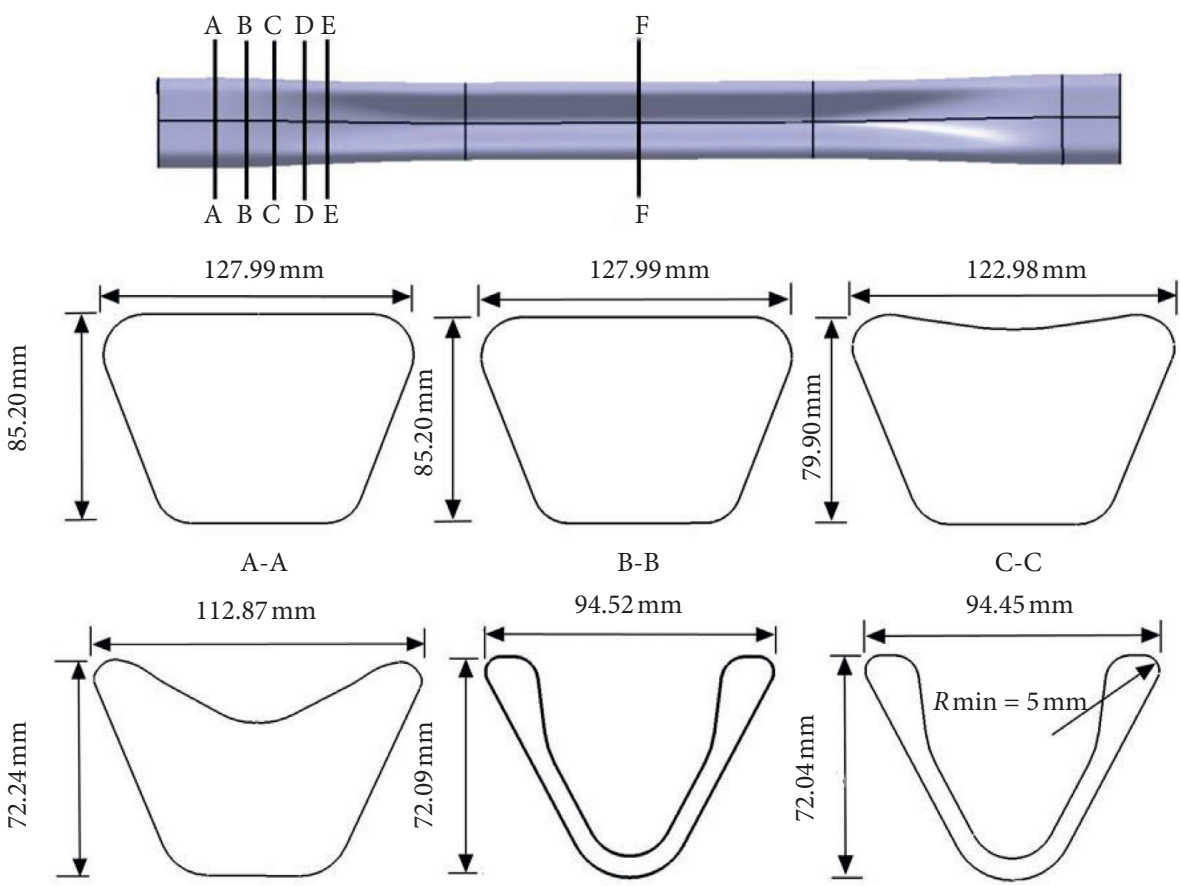

D-D

E-E

F-F

Figure 2: Section shape diagram of torsion beam.

TABle 1: Typical section perimeter table.

\begin{tabular}{lllllll}
\hline Cross section & A-A & B-B & C-C & D-D & E-E & F-F \\
\hline
\end{tabular}

\begin{tabular}{lllllll}
\hline Perimeter $(\mathrm{mm})$ & 364.14 & 365.13 & 340.97 & 330.48 & 354.36 & 354.88
\end{tabular}

When designing the inlay structure, attention should be paid to avoid the splicing line of the punch and the matrix, which should be staggered for a minimum of $3 \sim 5 \mathrm{~mm}$. Due to a complex cross section shape of the transition area on both part sides, an arc inlay block needs to be separately designed. The remaining inlay block parts are planar.

Front end of the plug is connected with the pipe billet, and the rear end is connected with the hydraulic cylinder piston rod. According to the shape of both part ends, the plug is designed as a cone type. Front end length of the plug is $15 \mathrm{~mm}$, and the middle part, which is in direct contact with the die, is $40 \mathrm{~mm}$ long. Junction of two parts is the sealing part, which is in contact with the end of the plug and the tube billet.
During hydraulic bulging, water injection holes on both piston rod sides are filled with water. The water flows into the mold from four plug outlet holes through an internal pressurization channel. In this paper, front end of the plug is directly in contact with the pipe fitting end. Based on axial feed force extrusion of hydraulic cylinders on both sides, small deformation is generated at the connection to achieve sealing [8]. Compared with the soft seal, this type of hard seal with direct contact between metals is suitable for highpressure environments. Furthermore, it demonstrates beneficial wear resistance and mechanical properties.

Liquid internal pressure of hydraulic bulging can generally reach approximately $300 \sim 400 \mathrm{MPa}$. In order to ensure that the axial force and cavity axis overlap during axial pressure after mold closing and that the hydraulic cylinder does not vibrate or bend, the upper die base is fixed in the top worktable surface chute via eight T-bolts on both sides $[9,10]$. Four corners of the upper die base are fixed with guide columns, and left and right sides are arranged with 


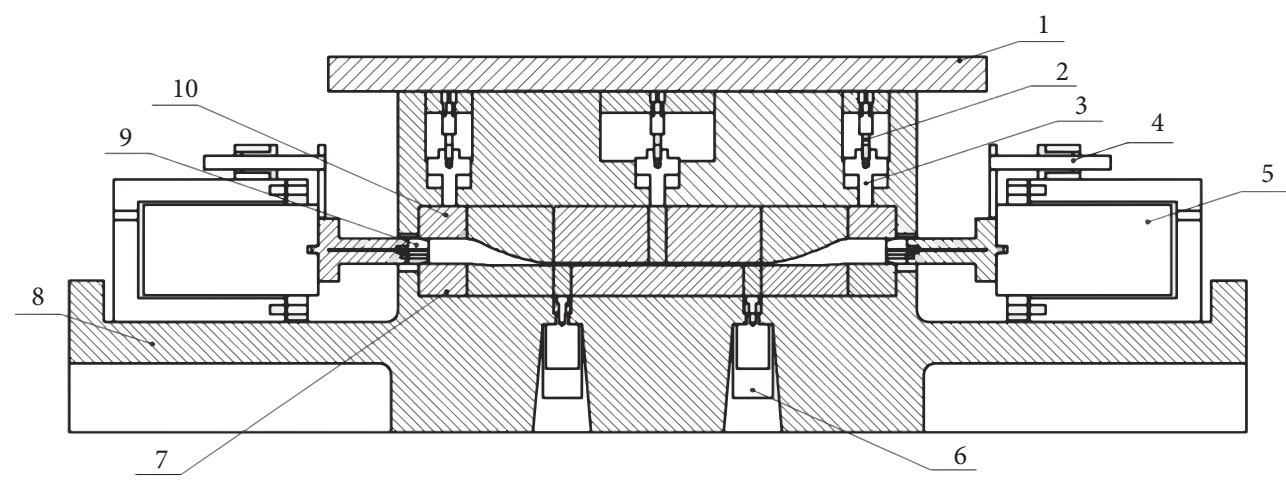

FIgURe 3: General assembly diagram of hydraulic expansion die for torsion beam: (1) upper die base; (2) cylinder; (3) pull-out rod of upper die; (4) displacement sensor; (5) hydraulic cylinder; (6) ejection cylinder; (7) matrix; (8) lower die base; (9) sealing plug; (10) punch.

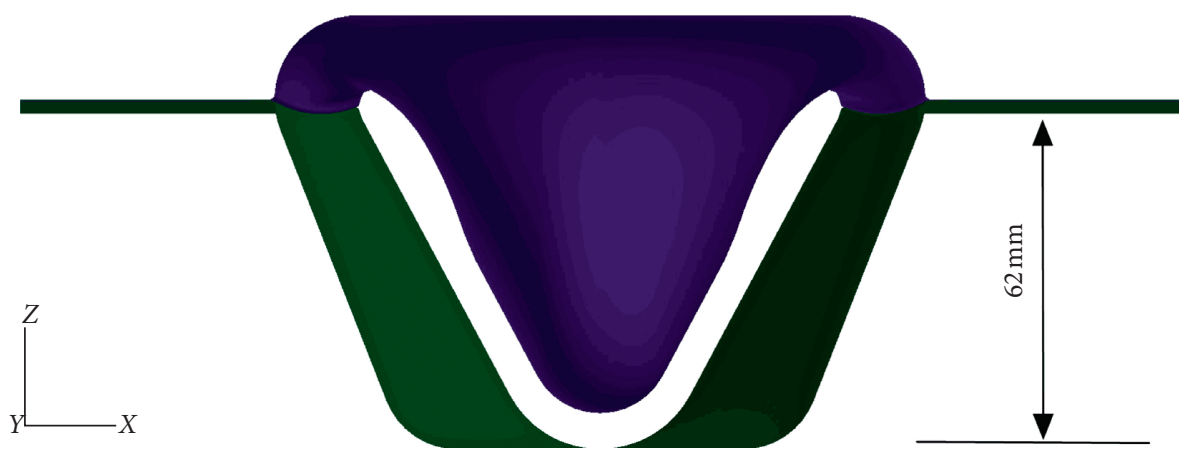

FIgURE 4: Location diagram of die parting line.

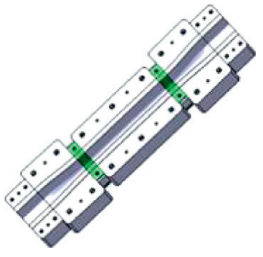

(a)

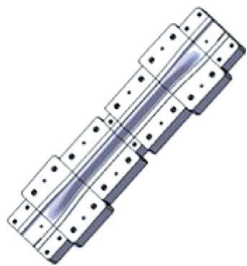

(b)

FIGURE 5: Structure drawing of punch and matrix insert: (a) structure of an inlaying matrix; (b) structure of an inlaying punch.

three-side guide blocks. When the die is closed, guide columns and guide blocks are matched with the corresponding guide sleeves and grooves of the lower die base to complete the guide. Therefore, hydraulic expansion type upper die base of automobile torsion beam is designed.

Since lower die base bears the weight of the entire die, its strength is very important [11]. The lower die base is fixed on the worktable by T-bolts. Guide sleeve corresponding to the upper die guide column is arranged at four corners of the lower die base. In addition, symmetrical guide block is also arranged in the middle, which is convenient for positioning during mold closing. Four limit plates are symmetrically arranged on both sides with respect to the middle. Their length $\times$ width $\times$ height is $50 \mathrm{~mm} \times 30 \mathrm{~mm} \times 5 \mathrm{~mm}$. The guide block plays a limit buffer role when the mold is closed. Hydraulic cylinders, which ensure axial feeding, are fixed on both sides on corresponding platforms via bolts.
3.2. Design of Hydraulic Control System for Synchronous Cylinders on Both Sides of Hydraulic Bulging Die. Automotive torsion beam is a type of symmetrical hollow pipe fitting. During hydraulic bulging die design, synchronization of hydraulic cylinders on both sides is particularly important. If poor synchronization is achieved, uneven material flow in the forming process may occur. Wrinkling, cracking, buckling, and other defects may be caused, thus affecting the forming quality of the final part. In order to solve these problems, synchronization of hydraulic control system for automobile torsion beam hydraulic bulging die is investigated in this paper. Combined with the actual operating conditions, a new axial feed control hydraulic system is designed. This system provides the feed required in the forming process, while simultaneously ensuring the synchronization accuracy of two cylinders via automatic deviation correction. 
In this paper, control volume for bidirectional shunt servo valve core displacement, which is represented by $X_{v}$, is designed. Controlled quantity is the transmission deviation, which is represented by $\Delta X_{p}$. When hydraulic cylinders no. 1 and no. 2 are not simultaneously active, the gear in the middle rotates to produce deviation displacement. Valve core displacement is used to change the oil outlets denoted as no. 1 and no. 2, so as to change the flow into the two hydraulic cylinders and finally make the displacement of the two hydraulic cylinders the same. The designed hydraulic control system is shown in Figure 6.

The oil supply branch supplies the hydraulic oil in the oil source to the hand-directional valve through the motor driving the hydraulic pump, presses the handle of the handdirectional valve, and connects the left end of the handdirectional valve to the loop; the hydraulic oil enters into the bidirectional shunt follow-up valve through the hand-directional valve. At this time, the valve core of the bidirectional shunt follow-up valve is in the middle of the chamber; that is, the section areas of oil outlet no. 1 and oil outlet no. 2 valve are equal, and the flows through outlets no. 1 and no. 2 into hydraulic cylinders no. 1 and no. 2 are equal. Because the two cylinders are of the same size, the two cylinders move at the same speed and in the opposite direction, and the speed of rack no. 1 and that of rack no. 2 connected with the two hydraulic cylinders are equal and opposite, which drives the gear to move. Since the speed values of the two racks are equal and opposite, the axis of the gear does not shift.

When the speed of hydraulic cylinder no. 1 is faster than that of hydraulic cylinder no. 2, rack no. 1 drives the axle center of the gear to shift to the left, and through the action of the connecting rod, the follow-up valve core moves to the right, thus reducing the cross section area of the valve port of oil outlet no. 1 . The section area of the valve port of oil outlet no. 2 is increased, so that the flow into hydraulic cylinder no. 1 decreases, the speed of hydraulic cylinder no. 1 decreases, the flow into hydraulic cylinder no. 2 increases, and the speed of hydraulic cylinder no. 2 increases, until the two cylinders are of equal speed.

Similarly, when the speed of hydraulic cylinder no. 1 is less than that of hydraulic cylinder no. 2 , rack no. 2 drives the shaft center of the gear to shift to the right, and through the action of the connecting rod, the follow-up valve core moves to the left, increasing the cross section area of the valve port of oil outlet no. 1, the section area of the valve port of oil outlet no. 2 is reduced, so that the flow into hydraulic cylinder no. 1 increases, the speed of hydraulic cylinder no. 1 increases, the flow into hydraulic cylinder no. 2 decreases, and the speed of hydraulic cylinder no. 2 decreases, until the two cylinders are of equal speed.

After the selection of hydraulic system components and calculation of system pressure loss, AMESim simulation software is used to simulate designed hydraulic system and explore whether the designed synchronous hydraulic system with automatic deviation correction can be established. The model is set to two different operating conditions, simulation time is set to $10 \mathrm{~s}$, and piston rod displacement is set to $80 \mathrm{~mm}$. The results show that piston rod displacement of two cylinders can be obtained. Displacement curve of two-way shunt servo valve middle spool is acquired. The system designed in this paper can achieve synchronous displacement of two cylinder piston rods. These rods have high synchronization, which meets the requirement of hydraulic expansion axial feed hydraulic system. When the same load pressure is applied to both cylinders, displacement curves of corresponding piston rods completely coincide, and the displacement error is equal to $0 \mathrm{~mm}$. When different load pressures are applied to two cylinders, the servo valve can adjust the flow via diversion port according to valve core displacement. Therefore, the displacement of two piston rods is consistent, and the automatic deviation correction function is realized. Hence, the system is successfully verified. The system model is shown in Figure 7.

In order to properly analyze automatic deviation correction hydraulic system designed in this paper, mathematical modeling for hydraulic control system is carried out in this section. The block diagram of the hydraulic control system is shown in Figure 8.

According to the above-established mathematical model, the flow equation of the following slide valve is obtained:

$$
q_{L}=\left(q_{1}+q_{2}\right)
$$

where $q_{L}$ is the load flow, $L / \mathrm{min} ; q_{1}$ is the flow rate into hydraulic cylinder no. $1, \mathrm{~L} / \mathrm{min}$; and $q_{2}$ is the flow rate into hydraulic cylinder no. 2, L/min.

According to fluid mechanics, valve orifice flow should satisfy Bernoulli equation:

$$
q_{1}=C_{d} A_{1} \sqrt{\frac{2\left(p_{s}-p_{1}\right)}{\rho}},
$$

where $C_{d}$ is the throttle flow coefficient; $p_{s}$ is the oil supply pressure, $\mathrm{MPa} ; \rho$ is the oil density, $\mathrm{kg} / \mathrm{m}^{3} ; A_{1}$ is the flow area of the throttle port of hydraulic cylinder no. $1, \mathrm{~m}^{2}$; and $p_{1}$ is the right chamber pressure of hydraulic cylinder no. 1, $\mathrm{MPa}$.

$$
q_{2}=C_{d} A_{2} \sqrt{\frac{2\left(p_{s}-p_{2}\right)}{\rho}},
$$

where $A_{2}$ is the flow area of hydraulic cylinder throttle port no. $2, \mathrm{~m}^{2}$, and $p_{2}$ is the left chamber pressure of hydraulic cylinder no. 2, MPa.

$$
q_{L}=C_{d} A_{1} \sqrt{\frac{2\left(p_{s}-p_{1}\right)}{\rho}}+C_{d} A_{2} \sqrt{\frac{2\left(p_{s}-p_{2}\right)}{\rho}} .
$$

Equation (4) is linearized to obtain pressure-flow characteristics near zero:

$$
q_{L}=\left(k_{q} x_{v}-k_{c} p_{L}\right)
$$

where $k_{q}$ is the flow gain factor and $k_{c}$ is the flow pressure coefficient. 


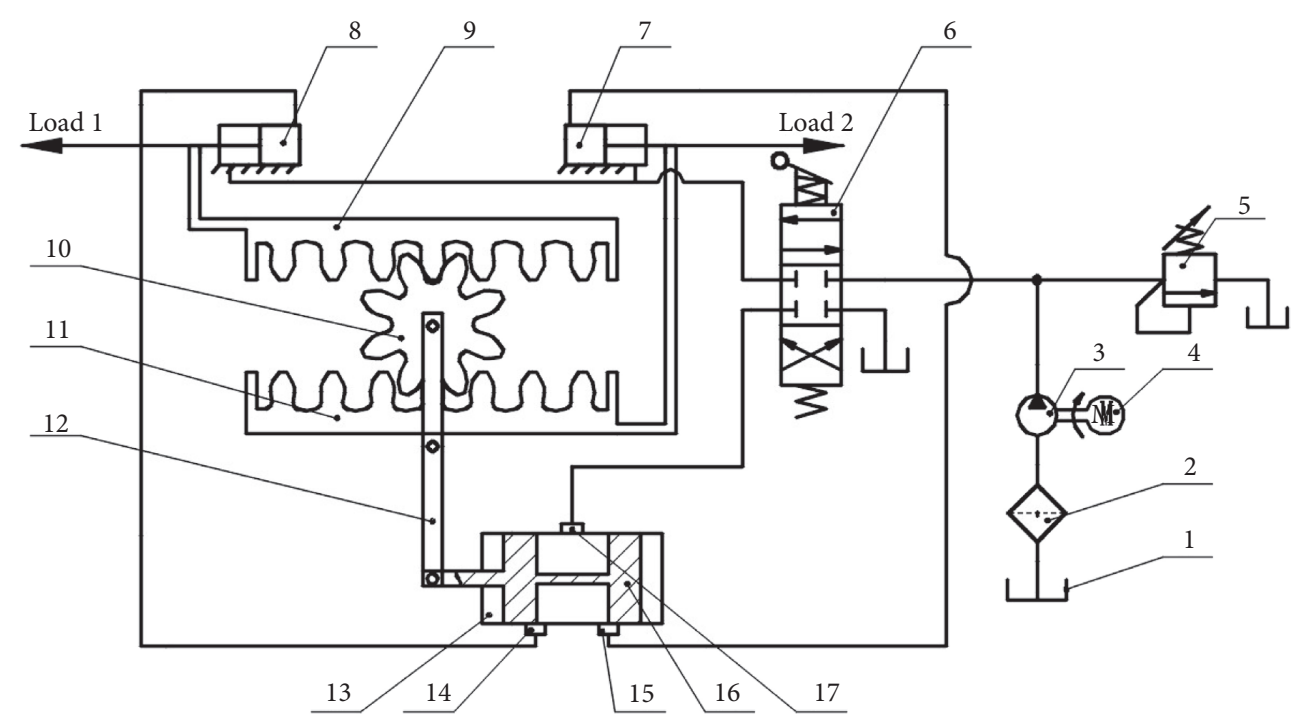

FIGURE 6: Schematic diagram of hydraulic control system: (1) oil source; (2) filter; (3) hydraulic pump; (4) motor; (5) overflow valve; (6) hand-directional valve; (7) hydraulic cylinder no. 2; (8) hydraulic cylinder no. 1; (9) rack no. 1; (10) displacement gear; (11) rack no. 2; (12) lever; (13) bidirectional shunt follow-up valve; (14) oil outlet no. 1; (15) oil outlet no. 2; (16) valve core; (17) oil inlet.

\section{(1)}

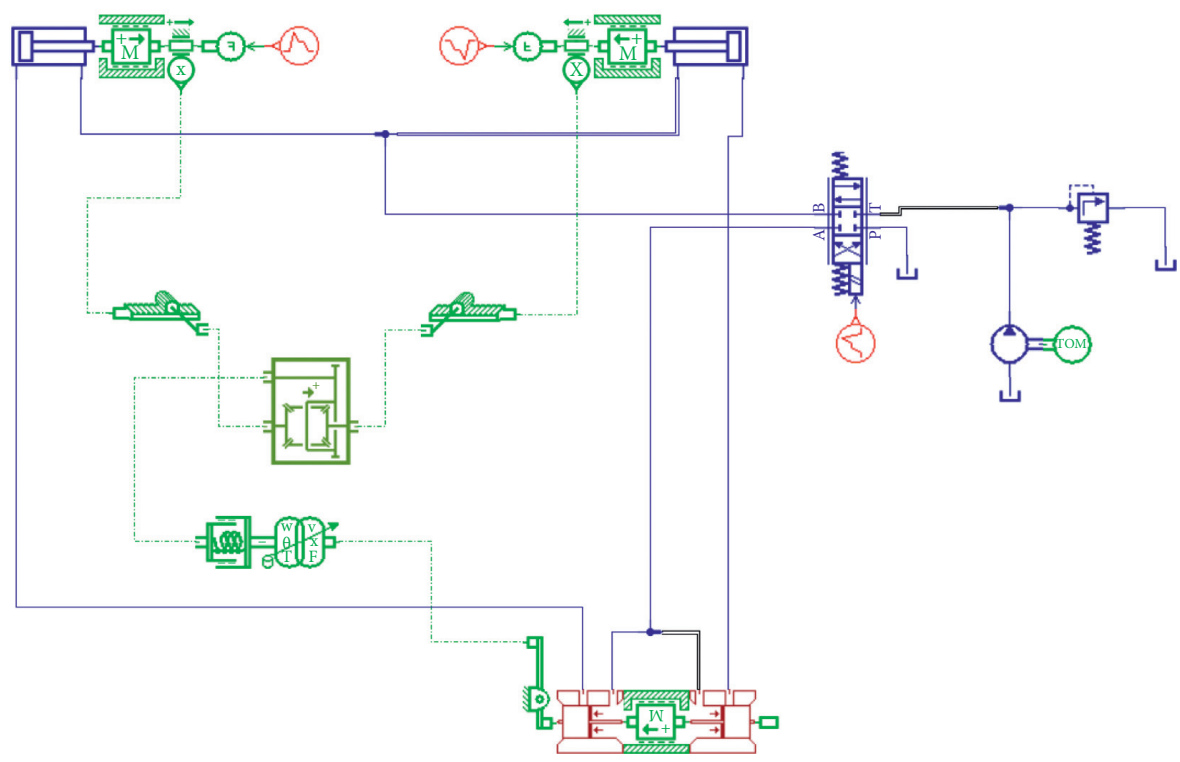

FIgURE 7: Modeling diagram of AMESim hydraulic system.

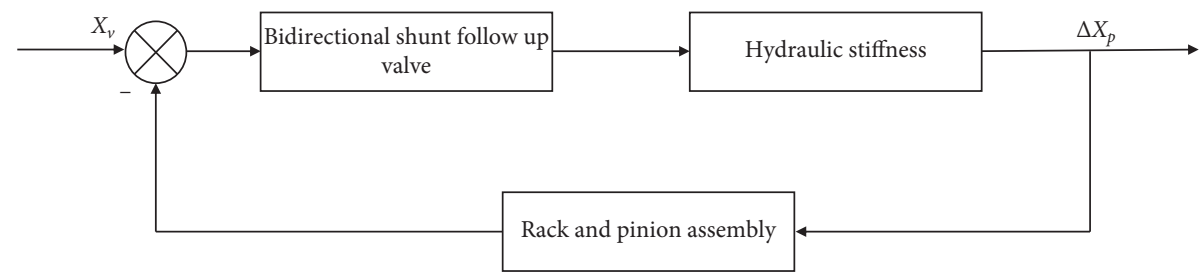

FIGURE 8: Block diagram of the hydraulic control system. 


$$
\begin{aligned}
k_{q} & =\frac{\partial q_{L}}{\partial x_{v}} \\
& =C_{d} W_{1} \sqrt{(1 / \rho)\left(p_{s}-p_{1}\right)}+C_{d} W_{2} \sqrt{(1 / \rho)\left(p_{s}-p_{2}\right)}, \\
k_{c} & =-\frac{\partial q_{L}}{\partial p_{L}} \\
& =\frac{C_{d} W x_{v} \sqrt{(1 / \rho)\left(p_{s}-p_{1}\right) p_{L}}}{2\left(p_{L}-p_{1}\right)}+\frac{C_{d} W x_{v} \sqrt{(1 / \rho)\left(p_{s}-p_{2}\right) p_{L}}}{2\left(p_{L}-p_{2}\right)},
\end{aligned}
$$

where $p_{L}$ is the load pressure, $\mathrm{kN}$, and $x_{v}$ is the valve core displacement, $m$.

Flow continuity equation of hydraulic cylinder is established. It is assumed that the connecting pipe is relatively short and thick, while pipe friction and pressure losses in the pipe as well as its dynamic state are assumed to be negligible. The pressure values in all working cavities of the hydraulic cylinder are equal, and the oil temperature and volume elastic modulus are assumed to be constant. Both internal and external hydraulic cylinder leakages are laminar; i.e., the load flow is equal to

$$
\begin{aligned}
& q_{1}=A_{p} \frac{\mathrm{d} x_{p 1}}{\mathrm{~d} t}+C_{i p} p_{L}+\frac{V_{1}}{\beta_{e}} \frac{\mathrm{d} p_{L}}{\mathrm{~d} t}, \\
& q_{2}=-A_{p} \frac{\mathrm{d} x_{p 2}}{\mathrm{~d} t}+C_{i p} p_{L}+\frac{V_{2}}{\beta_{e}} \frac{\mathrm{d} p_{L}}{\mathrm{~d} t}, \\
& q_{L}=\left(q_{1}+q_{2}\right),
\end{aligned}
$$

where $A_{p}$ is the effective area of hydraulic cylinder piston rod-free cavity, $\mathrm{m}^{2} ; x_{p 1}$ is the displacement of hydraulic cylinder piston rod no. $1, m ; x_{p 2}$ is the displacement of hydraulic cylinder piston rod no. $2, m ; C_{i p}$ is the leakage coefficient in hydraulic cylinder; $V_{1}$ is the volume of hydraulic cylinder inlet chamber no. $1, \mathrm{~m}^{3} ; V_{2}$ is the volume of hydraulic cylinder inlet chamber no. $2, \mathrm{~m}^{3}$; and $\beta_{e}$ is the effective volume modulus of elasticity (including the mechanical flexibility of oil, connecting pipes, and cylinders).

$$
\Delta x_{p}=\left(x_{p 1}-x_{p 2}\right)
$$

where $\Delta x_{p}$ is the transmission deviation, $m$.

$$
\begin{aligned}
& V_{t}=V_{1}+V_{2}, \\
& q_{L}=A_{p} \frac{\mathrm{d} x_{p}}{\mathrm{~d} t}+2 C_{i p} p_{L}+\frac{V_{t}}{\beta_{e}} \frac{\mathrm{d} p_{L}}{\mathrm{~d} t},
\end{aligned}
$$

where $V_{t}$ is the total compression volume, $\mathrm{m}^{3}$.

Based on the aforementioned relations, force balance equation and load of hydraulic cylinder are established. According to Newton's second law, the balance equation of the output force and the load force of hydraulic cylinder can be obtained as follows:

$$
A_{p} p_{L}=m_{t} \frac{\mathrm{d}^{2} x_{p}}{\mathrm{~d} t^{2}}+B_{p} \frac{\mathrm{d} x_{p}}{\mathrm{~d} t}+K x_{p}+F_{L}
$$

where $m_{t}$ is the total mass of the piston and the load converted to the piston, $\mathrm{kg} ; B_{p}$ is the viscous damping coefficient of piston and load; $K$ is the load spring stiffness; and $F_{L}$ is any accidental load acting on the piston, $\mathrm{kN}$.

Equations 5, (10), and (11) represent three basic equations of valve controlled hydraulic cylinder, which fully describe dynamic characteristics of valve controlled hydraulic cylinder. Laplace transform of three equations can be written as

$$
\begin{aligned}
Q_{L} & =K_{q} X_{v}-K_{c} P_{L}, \\
Q_{L} & =A_{p} s X_{p}+2 C_{i p} P_{L}+\frac{V_{t}}{\beta_{e}} s P_{L}, \\
A_{p} P_{L} & =m_{t} s^{2} \Delta X_{p}+B_{p} s \Delta X_{p}+K \Delta X_{p}+F_{L} .
\end{aligned}
$$

If only instruction signal $X_{v}$ is present, intermediate variables $Q_{L}$ and $P_{L}$ can be eliminated:

$$
\Delta X_{p}=\frac{\left(K_{q} / A_{p}\right) X_{v}-\left(1 / A_{p}^{2}\right)\left(2 C_{i p}+\left(V_{t} / \beta_{e}\right) s+K_{c}\right) F_{L}}{\left(m_{t} V_{t t} / \beta_{e} A_{p}^{2}\right)+\left(\left(2 m_{t} C_{i p} / A_{p}^{2}\right)+\left(2 m_{t} K_{c} / A_{p}^{2}\right)+\left(B_{p} V_{t} / \beta_{e} A_{p}^{2}\right)\right) S^{2}+\left(\left(2 B_{p} C_{i p} / A_{p}^{2}\right)+\left(B_{p} K_{c} / A_{p}^{2}\right)+\left(K V_{t} / \beta_{e}\right) A_{p}^{2}\right) S+\left(2 C_{i p}+K_{C} / A_{p}^{2}\right) K} .
$$

Most servo system loads consider inertia load as the main objective, while elastic load can be assumed to be negligible due to its minor effect. Since velocities $\left(\left(2 m_{t} C_{i p} / A_{p}^{2}\right) S\right.$, $\left.\left(2 B_{p} C_{i p} / A_{p}^{2}\right) S,\left(B_{p} K_{c} / A_{p}^{2}\right)\right)$ generated by the leakage coefficient $\left(C_{i p}\right)$ and viscous damping coefficient $\left(B_{p}\right)$ in the hydraulic cylinder are much smaller than the moving speed of the piston, the above equation can be disregarded. When $K=0$, the transfer function can be simplified as 


$$
\Delta X_{p}=\frac{\left(K_{q} / A_{p}\right) X_{v}-\left(1 / A_{p}^{2}\right)\left(2 C_{i p}+\left(V_{t} / \beta_{e}\right) s+K_{c}\right) F_{L}}{\left(\left(S^{2} / \omega_{0}^{2}\right)+\left(2 \xi / \omega_{0}\right) S+1\right) S} .
$$

When feedback gain $K_{f}=1 / 2$ is added, the transfer function for input instruction $X_{v}$ can be written as

$$
\begin{aligned}
G(s) & =\frac{\Delta X_{p}}{X_{v}} \\
& =\frac{K_{q} K_{f} / A_{p}}{\left(\left(S^{2} / \omega_{0}^{2}\right)+\left(2 \xi / \omega_{0}\right) S+1\right) S} .
\end{aligned}
$$

Once known parameters are inserted into the equation, the following expression is obtained:

$$
\begin{aligned}
G(s) & =\frac{\Delta X_{p}}{X_{v}} \\
& =\frac{39.48}{\left(\left(S^{2} / 221^{2}\right)+(0.4 / 221) S+1\right) S} .
\end{aligned}
$$

Equation (16) is loaded into Simulink environment to obtain the simulation model shown in Figure 9. Step response curve of the system is finally obtained (Figure 10.)

When the step signal is acting as the input signal, the system reaches a stable state at approximately $0.2 \mathrm{~s}$ without overshoot. It can be concluded that the output signal is consistent with the input signal; i.e., the performance is satisfactory.

\section{Automobile Torsion Beam Hydraulic Bulging Simulation Based on DYNAFORM}

4.1. Simulation of Hydraulic Bulging Torsion Beam. Typical process of torsion beam manufacturing is stamping. In this paper, in order to improve the end forming condition of parts and quality of the final product, traditional stamping is improved. Furthermore, the end shaping is simultaneously carried out during the stamping process. Movement mode of the preform die is as follows: during the downward process of the upper die, the plug at both ends is fed $415 \mathrm{~mm}$ axially for shaping purposes until the die is fully closed. The preform model is designed according to the requirements and shown in Figure 11.

First, CATIA software is employed to establish the selected pipe blank model, whose size is $\varnothing 104 \mathrm{~mm} \times 1290 \mathrm{~mm} \times 3 \mathrm{~mm}$. Then, the model is imported into DYNAFORM for meshing with prebuilt IGS files of punch, matrix, and plug surface. DP780 high-strength steel is selected as the material. Since die and plug can be regarded as rigid bodies, linear loading path is adopted. The overall simulation time is $0.02 \mathrm{~s}$, and software default trapezoidal loading path is adopted for the mold closing speed. The mold closing is completed at $0 \sim 0.02 \mathrm{~s}$ descending from the upper die, and the axial displacement of the plug is equal to $415 \mathrm{~mm}$ during $0 \sim 0.01 \mathrm{~s}$ timespan.

As shown in Figures 12 and 13, no wrinkling and cracking occurred during the preforming process.
Maximum thinning rate of parts is equal to $7.889 \%$, while maximum thickening rate is equal to $16.188 \%$, both of which are within a reasonable range. Maximum thinning rate is located at the junction of the middle V-shaped zone and the transition zone, which occurs because this is the place where the tube body first gets in contact with the punch, thus altering the shape most significantly. This is in accordance with the actual situation. The maximum thickening position is at the junction of the transition area and the port area. This is due to the cross section shape of this area being relatively complex, which makes it easy for material to accumulate. Torsion beam can be flattened by later applying internal pressure via liquid, which is in accordance with the actual processing situation. Therefore, it can be concluded that torsion beam performance is adequate.

4.2. Simulation of Torsion Beam Hydraulic Bulging. According to the mold design, mold cavity of hydraulic bulging is consistent with the final part. First, IGS files of each die surface modeled by CATIA are imported into DYNAFORM and meshed. Simultaneously, the dynain file (the forming results with stress and strain) of preformed tube blank is imported. After establishing the finite element model, simulation parameters are added. According to the results of the torsion beam structure design, high-strength steel material denoted as DP780 is employed. Initial yield pressure and integral pressure are calculated as reference values. Since the integral pressure is approximately equal to $1 / 10 \sim 1 / 4$ of the material yield strength [12], the support pressure is obtained as $31 \mathrm{MPa}$ for the comprehensive preforming of the torsion beam. Integral pressure is equal to $180 \mathrm{MPa}$. Friction coefficient is 0.125 , and the loading time is defined as $0.02 \mathrm{~s}$.

The entire molding process is also divided into two stages. The first stage, feeding pressure stage, lasts for $0.01 \mathrm{~s}$. Then, the bulging stage occurs and lasts for $0.01 \sim 0.02 \mathrm{~s}$. The results indicate that the feeding amount behaves as linear loading, with the ideal feeding amount being a minimum of $30 \mathrm{~mm}$. The internal pressure is equal to $0 \sim 0.01 \mathrm{~s}$, while a certain amount of bulging is carried out along the linear loading path. The internal pressure is $180 \mathrm{MPa}$ in $0.01 \sim 0.015 \mathrm{~s}$ range, followed by the pressure maintaining molding which is carried out in $0.015 \sim 0.02 \mathrm{~s}$ range. This, in turn, improves the molding effect. The molding effect is shown in Figure 14.

In Figure 15, distribution of torsion beam wall thickness reduction rate after forming according to the above loading path is shown. For the convenience of discussion, four characteristic areas, $A, B, C$, and $D$, are marked in the figure [13]. Overall, the simulation results of torsion beam hydraulic bulging are good and meet the actual processing needs.

Areas $A$ and $D$ at the side edge of the end represent main thickness reduction areas. Area $A$ is located in the contact area between both ends of the plug and the tube billet, where the material has relatively large fluidity. Moreover, highpressure liquid at the end accelerates wall thickness thinning. Maximum thickness reduction appears in $D$ region. This is 


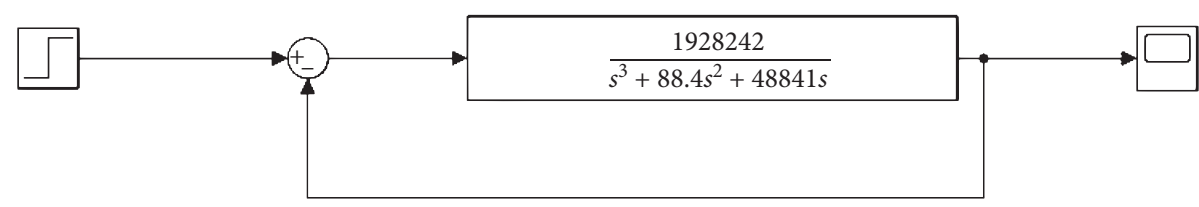

FiguRE 9: Simulation diagram of hydraulic synchronous system transfer function.

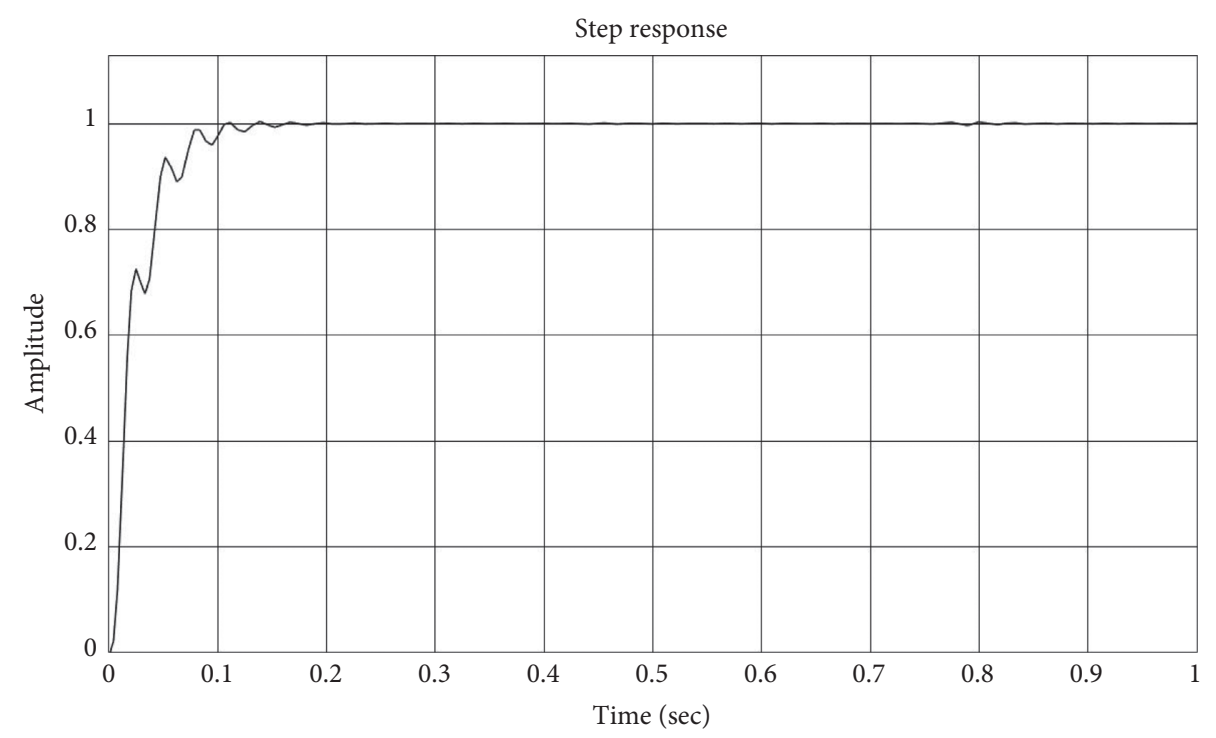

FIgURE 10: Step response curve of hydraulic synchronous system.

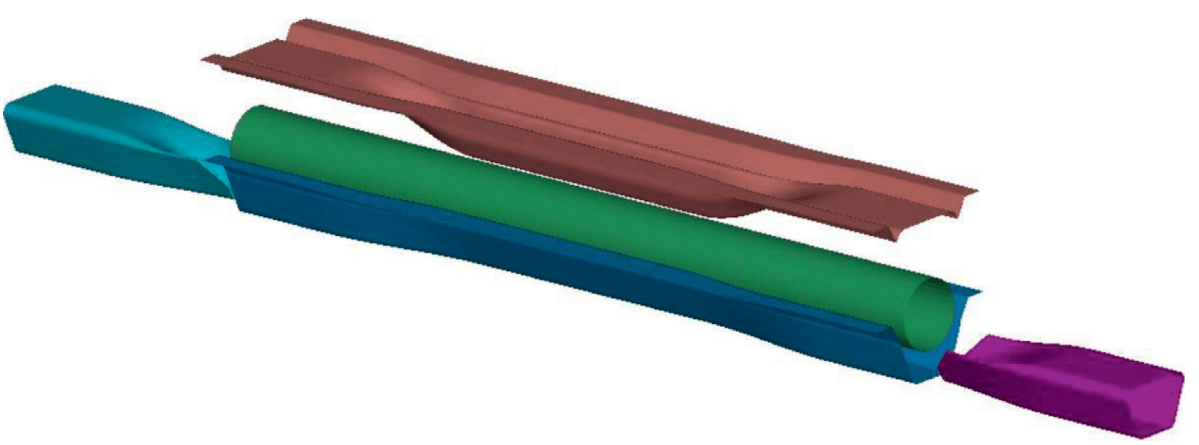

Figure 11: Preforming process scheme diagram.

because the area is the contact area between the first punch and preforming parts. At the border of $\mathrm{V}$-shaped area and transition area, mold clamping shape changes significantly. Axial and circular tensile stresses cause wall thickness reduction. More specifically, the minimum value of wall thickness is equal to $2.713 \mathrm{~mm}$ with the corresponding maximum thinning rate of $9.577 \%$.

Transition section $B$ represents main thickening area, which is caused by excessive hoop expansion during mold closing, thus resulting in hoop compression. Maximum $B$ area wall thickness is $3.527 \mathrm{~mm}$, which corresponds to a maximum thickening rate of $17.574 \%$ and a maximum wall thickness difference of $0.814 \mathrm{~mm}$. Compared with preforming results, it is found that the change is very small. This can be attributed to irregularity of area shape. When compared with other areas, cross-sectional shape change is relatively small. This area has been adequately formed in the early stage, and the later hydraulic bulging only improves the film precision of the fillet part.

\section{Optimization of Process Parameters Based on Orthogonal Experimental Design and Taguchi Algorithm}

5.1. Orthogonal Experiment and Evaluation Index of Torsion Beam Hydraulic Bulging. In the process of automobile torsion beam hydraulic bulging, many factors affect the 


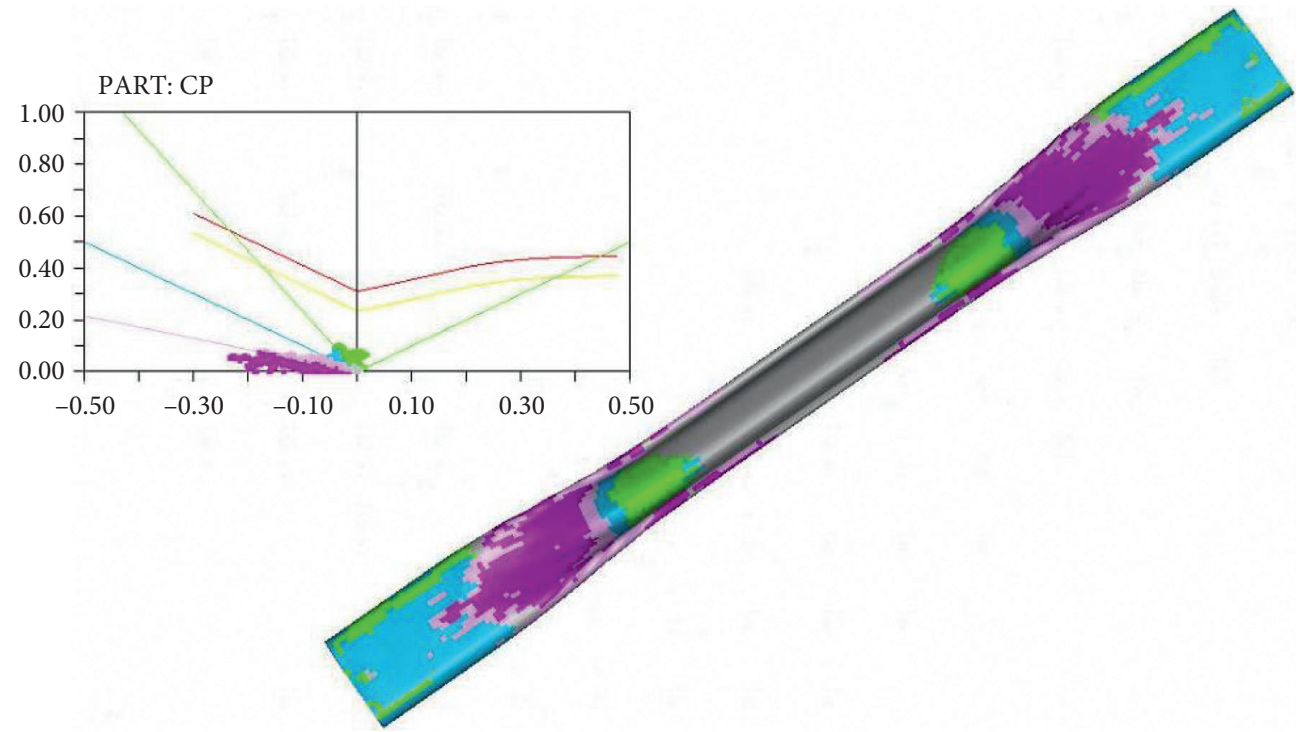

Figure 12: FLD of torsion beam preform.
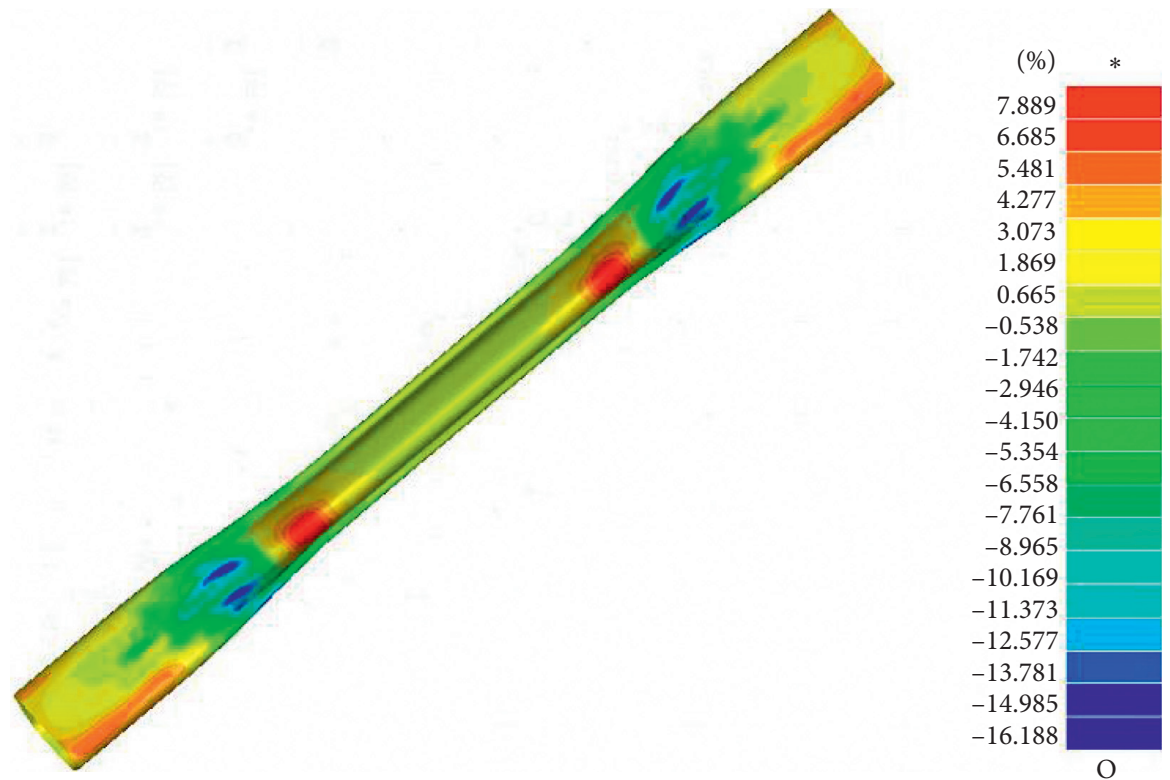

FIGURE 13: Nephogram of torsion beam wall thinning rate.

forming quality of the final product, such as the selection of the initial pipe diameter, the loading path of internal pressure, and the feeding quantity. Based on the cost effectiveness, experimental research on these factors and levels cannot be carried out individually. In this paper, the orthogonal experiment method is applied to hydraulic bulging of torsion beam. According to the orthogonal table, representative simulated verification process parameter combination is selected.

Based on previous discussion and results, wall thickness change is considered as one of the main factors affecting the product surface quality and assembly accuracy. If the thickness of each product part changes beyond the allowable range, wrinkling, warping, and rupture defects can occur.
This, in turn, affects the forming quality of the parts. Therefore, maximum thinning and maximum thickening rates are selected as evaluation indexes in this paper.

5.2. Orthogonal Experimental Table and Analysis of Results. In this paper, four process parameters are selected as experimental level factors: supporting pressure, molding pressure, friction coefficient, and feeding quality. In order to ensure the experimental effect, the range of process parameters should be as large as possible [14]. By assuming negligible interaction between process parameters, four levels are evenly selected, and design level factors are shown in Table 2. 


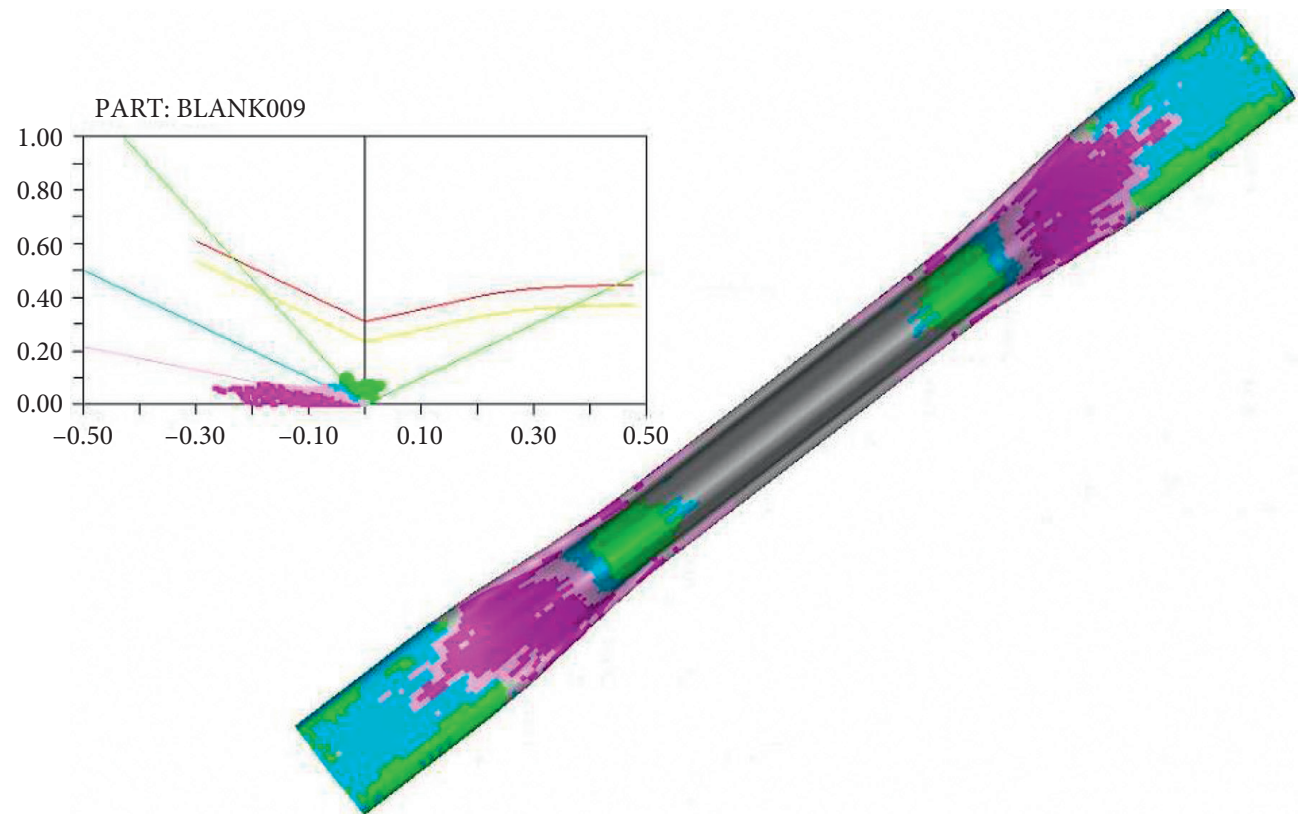

FIGURE 14: FLD of torsion beam hydraulic expansion.
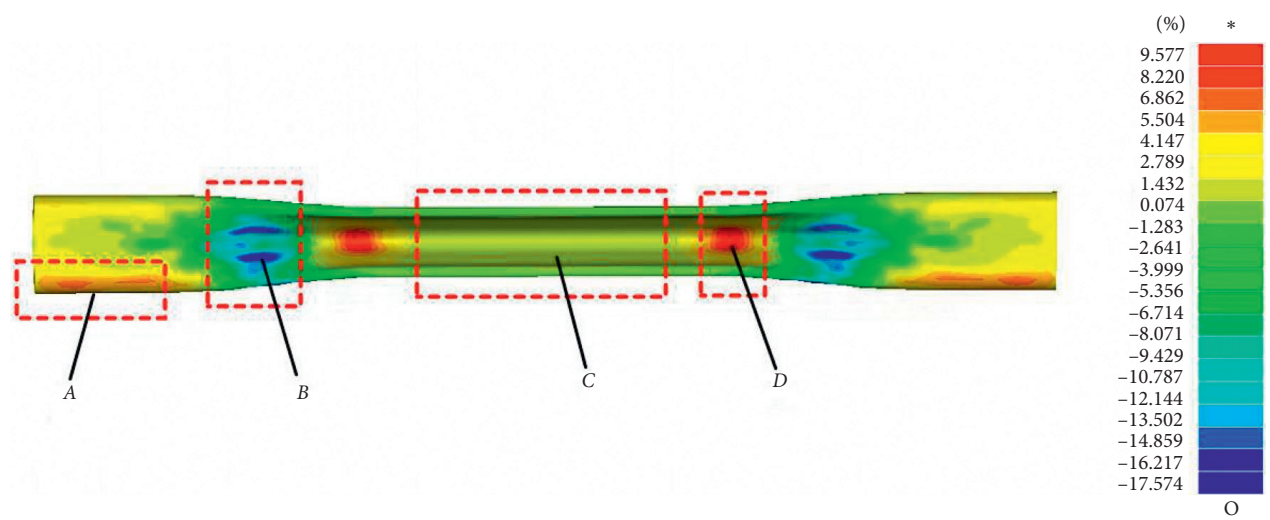

Figure 15: Nephogram of torsion beam hydraulic bulging wall thinning rate.

TABLE 2: Level factor setting table.

\begin{tabular}{lcccc}
\hline & & & Factor & \\
Level & $A$ & $B$ & $C$ & $D$ \\
& Supporting pressure $(\mathrm{MPa})$ & Molding pressure $(\mathrm{MPa})$ & Feeding quality (mm) & Friction coefficient \\
\hline 1 & 20 & 150 & 25 & 0.075 \\
2 & 40 & 180 & 30 & 0.1 \\
3 & 60 & 210 & 35 & 0.125 \\
4 & 80 & 240 & 40 & 0.15 \\
\hline
\end{tabular}

Level factors are input into the orthogonal table to generate 16 groups of process parameter combinations. These data groups are, respectively, simulated and analyzed, and corresponding maximum thinning rate and maximum thickening rate are obtained, as shown in Table 3 .

In the orthogonal table, if one wishes to obtain the index value at the $j$ - th level of column $i$, average number $R_{i j}$ of the sum of the experimental indexes in this column can be used, where $i=1,2,3,4, \ldots, p$ and $j=1,2,3,4, \ldots, m$. The index range $R_{i}$ is as follows:

$$
R_{i}=\left(R_{i j \max }-R_{i j \min }\right),
$$

where $R_{i j \max }$ is the maximum mean value of indicators at different levels and $R_{i j \min }$ is the minimum mean value of indicators at different levels. 
TABLE 3: Experimental design and results.

\begin{tabular}{lcccccc}
\hline \multirow{2}{*}{ Test number } & \multicolumn{3}{c}{ Factor } & \multicolumn{2}{c}{ Indicator } \\
& $A$ & $B$ & $C$ & $D$ & Maximum thinning rate & Maximum thickening rate \\
\hline 1 & 20 & 150 & 25 & 0.075 & 9.01 & 16.52 \\
2 & 20 & 180 & 30 & 0.1 & 8.53 & 17.52 \\
3 & 20 & 210 & 35 & 0.125 & 9.01 & 20.89 \\
4 & 20 & 240 & 40 & 0.15 & 9.53 & 18.79 \\
5 & 40 & 210 & 40 & 0.075 & 10.7 & 20.42 \\
6 & 40 & 240 & 35 & 0.1 & 8.77 & 16.58 \\
7 & 40 & 150 & 30 & 0.125 & 8.62 & 17.56 \\
8 & 40 & 180 & 25 & 0.15 & 9.45 & 10.18 \\
9 & 60 & 240 & 30 & 0.075 & 9.67 & 18.91 \\
10 & 60 & 210 & 25 & 0.1 & 8.76 & 17.66 \\
11 & 60 & 180 & 40 & 0.125 & 9.58 & 17.64 \\
12 & 60 & 150 & 35 & 0.15 & 9.59 & 16.54 \\
13 & 80 & 180 & 35 & 0.075 & 9.91 & 19.8 \\
14 & 80 & 150 & 40 & 0.1 & 8.72 & 19.26 \\
15 & 80 & 240 & 25 & 0.125 & 0.15 & \\
16 & 80 & 210 & 30 & & & \\
\hline
\end{tabular}

TABLE 4: Range analysis table of maximum thinning rate.

\begin{tabular}{lcccr}
\hline Level & $A$ & $B$ & $C$ & \\
\hline Mean 1 & 9.085 & 9.033 & 9.403 & 9.393 \\
Mean 2 & 9.405 & 9.335 & 9.118 & 9.973 \\
Mean 3 & 9.473 & 9.278 & 9.458 & 9.270 \\
Mean 4 & 9.450 & 9.768 & 9.435 & 8.778 \\
Range & 0.365 & 0.735 & 0.340 & 1.195 \\
\hline
\end{tabular}

By employing 17, range of maximum thinning rate under different factor levels can be obtained, as shown in Table 4

Range presented in Table 4 reflects the influence relationship of maximum thinning rate at the factor level. According to Table 4, friction coefficient has the greatest influence on maximum thinning rate of automotive torsion beam hydraulic bulging. The influence degree of each factor on the index is as follows: friction coefficient $>$ molding pressure $>$ supporting pressure $>$ feeding quality. Material thickness reduction is a process of mutual restriction by many factors. According to the above obtained range analysis, the combination should be selected as $A_{1} B_{1} C_{2} D_{4}$. The molding effect is shown in Figure 16. In other words, the supporting pressure is $20 \mathrm{MPa}$, the molding pressure is $150 \mathrm{MPa}$, the feeding rate is $30 \mathrm{~mm}$, and the friction coefficient is 0.15 . DYNAFORM simulation analysis results are shown in Figure 17. Maximum thinning rate of parts is $8.591 \%$, maximum thickening rate is $16.579 \%$, and maximum thinning rate reaches the minimum. The results are in accordance with the range analysis.

Next, maximum thickening rate is analyzed. It is observed that maximum thickening rate has a greater impact on parts. If the maximum product thickening amount is large enough, it may lead to wrinkling defects of the torsion beam and consequently inability to assemble the product. The range of maximum thickening rate under different factor levels can be obtained as shown in Table 5.
The analysis shows that the molding pressure has a significant influence on maximum thickening rate of the product. Influence degree of four factors can be classified as follows: molding pressure $>$ friction coefficient $>$ supporting pressure $>$ feeding quality. The optimal parameter combination obtained by range analysis is $A_{2} B_{1} C_{2} D_{1}$, molding effect is shown in Figure 18, supporting pressure is $40 \mathrm{MPa}$, molding pressure is $150 \mathrm{MPa}$, feeding quality is $30 \mathrm{~mm}$, and friction coefficient simulated by DYNAFORM is 0.075 . As shown in Figure 19, maximum thinning rate is $9.848 \%$, maximum thickening rate is $16.504 \%$, and maximum thickening rate reaches the minimum. The results are in line with the conducted range analysis.

\subsection{Torsion Beam Hydraulic Bulging Parameter Optimization} Based on Taguchi Algorithm. Many evaluation indexes are employed for hydraulic bulging quality of an automobile torsion beam. In this paper, maximum thinning rate and maximum thickening rate are selected as forming evaluation indexes. However, by assuming negligible simultaneous influence of two evaluation indexes on parts range analysis, orthogonal experiment is employed to investigate two evaluation indexes. Therefore, Taguchi algorithm is utilized to combine them by weight coefficient into an evaluation index $Y$ for comprehensive analysis [15]. Proportions of maximum thinning rate and maximum thickening rate of wall thickness before and after molding are set to 50\% [16]. As shown in Table 6, supporting pressure, molding pressure, 


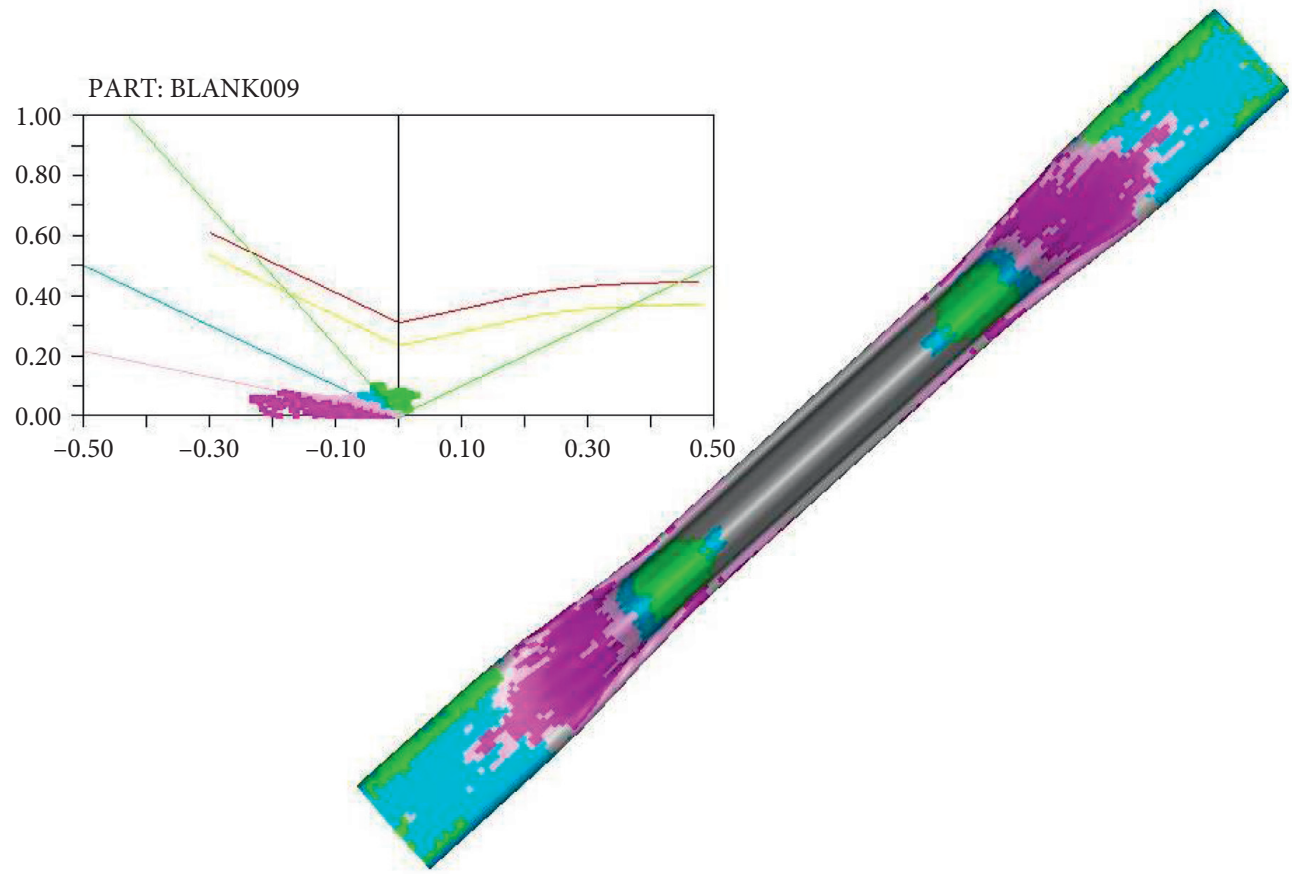

Figure 16: FLD of $A_{1} B_{1} C_{2} D_{4}$ combination.
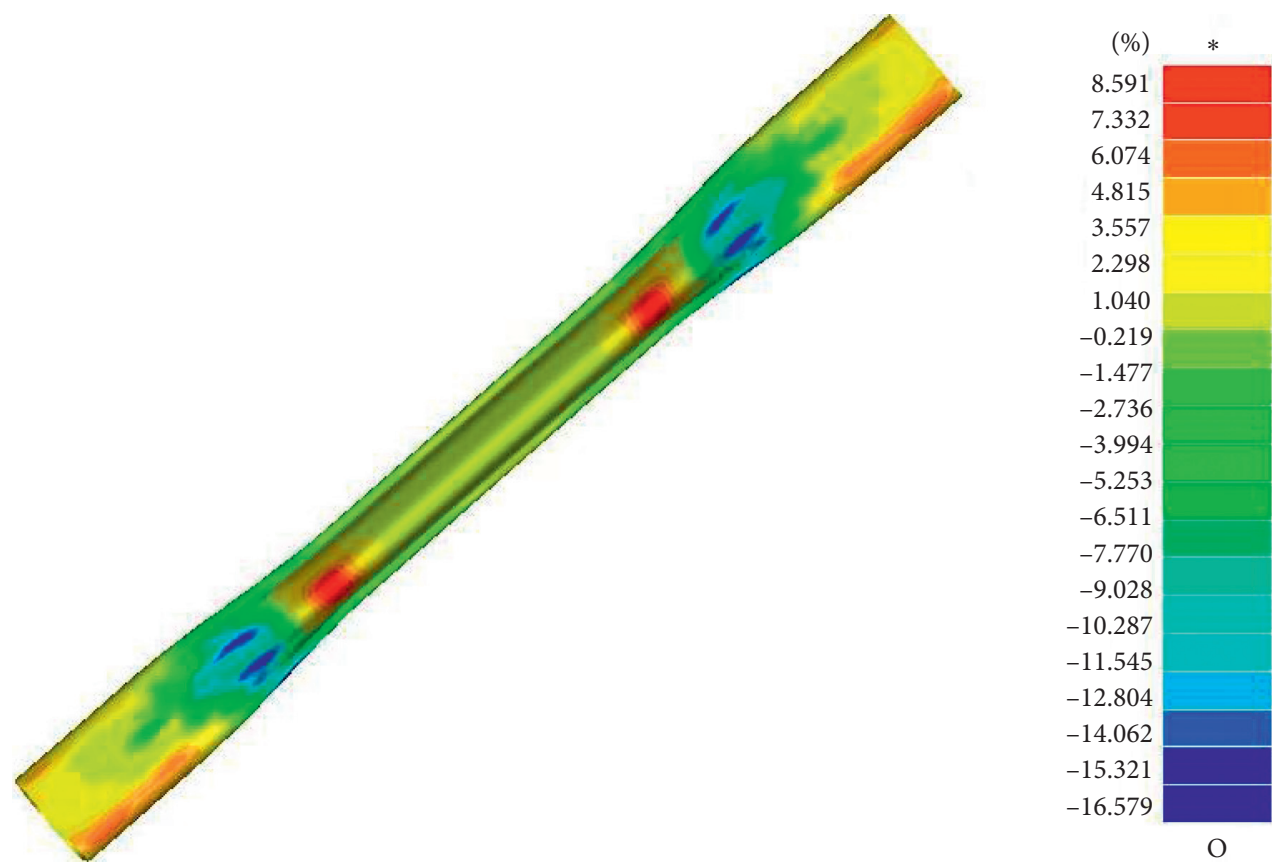

Figure 17: Nephogram of thinning rate of $A_{1} B_{1} C_{2} D_{4}$ combination.

TABLE 5: Range analysis table of maximum thickening rate.

\begin{tabular}{lcccc}
\hline Level & $A$ & $B$ & $C$ & $D$ \\
\hline Mean 1 & 18.483 & 16.570 & 18.448 & 18.273 \\
Mean 2 & 18.338 & 17.585 & 18.385 & 18.348 \\
Mean 3 & 18.348 & 18.990 & 18.415 & 18.510 \\
Mean 4 & 18.550 & 20.573 & 18.470 & 18.588 \\
Range & 0.213 & 4.003 & 0.085 & 0.315 \\
\hline
\end{tabular}




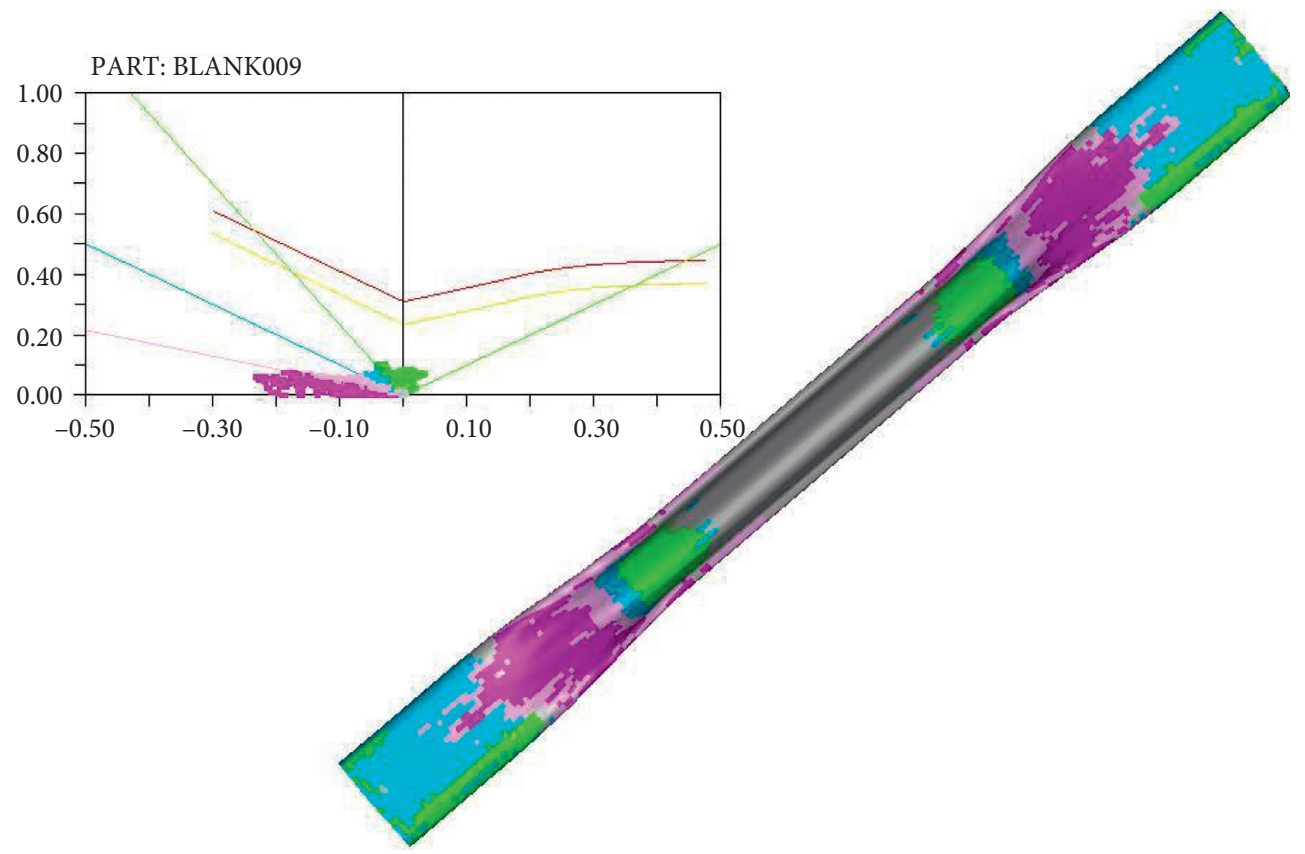

Figure 18: FLD of $A_{2} B_{1} C_{2} D_{1}$ combination.
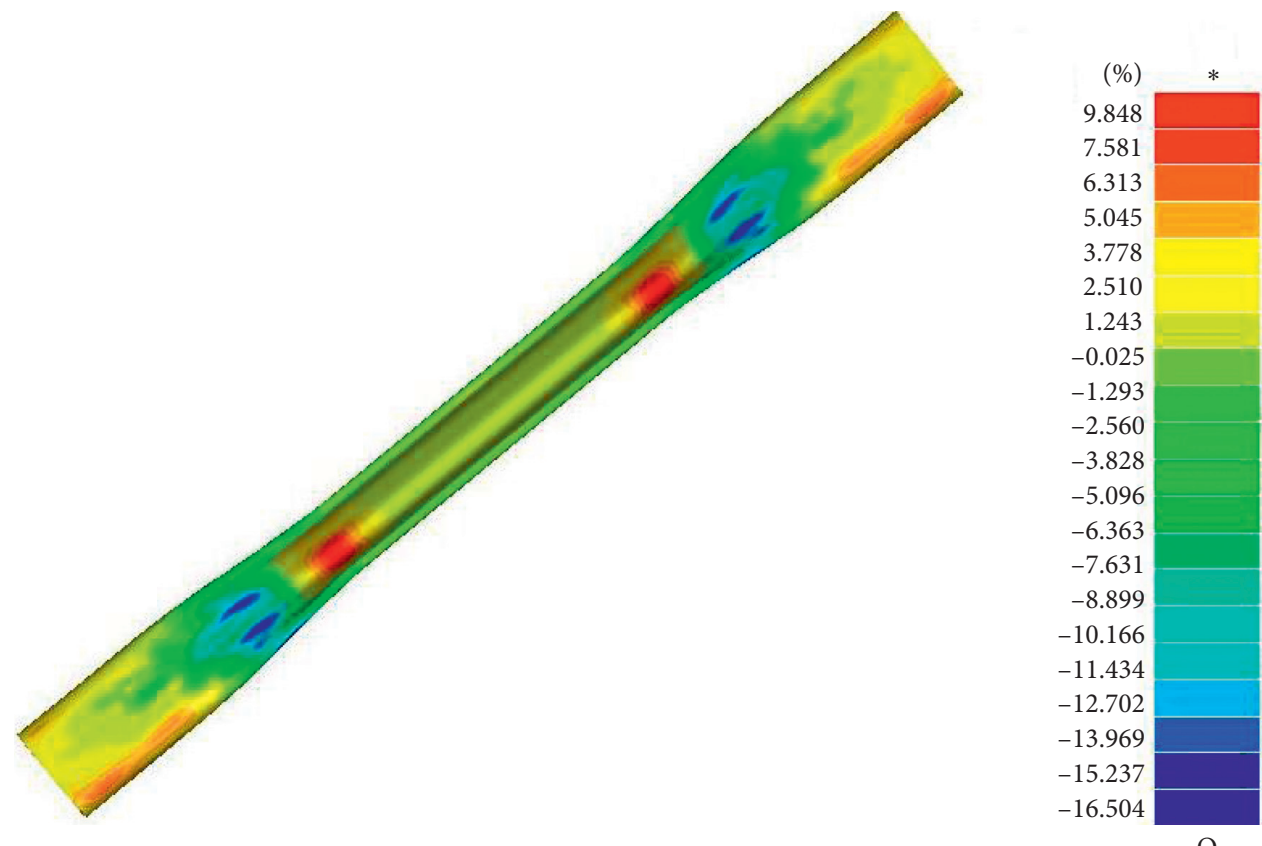

FIgURE 19: Nephogram of thinning rate of $A_{2} B_{1} C_{2} D_{1}$ combination.

TABLE 6: Level factor setting table.

\begin{tabular}{lcccc}
\hline Level & & Factor & & \\
& $A$ supporting pressure $(\mathrm{MPa})$ & $B$ molding pressure $(\mathrm{MPa})$ & $C$ feeding quality $(\mathrm{mm})$ & $D$ friction coefficient \\
\hline 1 & 20 & 150 & 25 & 0.075 \\
2 & 40 & 180 & 30 & 0.1 \\
3 & 60 & 210 & 35 & 0.125 \\
4 & 80 & 240 & 40 & 0.15 \\
\hline
\end{tabular}


TABLE 7: Orthogonal inner table.

\begin{tabular}{|c|c|c|c|c|c|c|}
\hline \multirow{2}{*}{ Test number } & \multicolumn{4}{|c|}{ Factor } & \multicolumn{2}{|c|}{ Indicator } \\
\hline & $A$ & $B$ & $C$ & $D$ & Maximum thinning rate & Maximum thickening rate \\
\hline 1 & 20 & 150 & 25 & 0.075 & 9.01 & 16.52 \\
\hline 2 & 20 & 180 & 30 & 0.1 & 9.53 & 17.52 \\
\hline 3 & 20 & 210 & 35 & 0.125 & 8.79 & 19 \\
\hline 4 & 20 & 240 & 40 & 0.15 & 9.01 & 20.89 \\
\hline 5 & 40 & 210 & 40 & 0.075 & 9.53 & 18.79 \\
\hline 6 & 40 & 240 & 35 & 0.1 & 10.7 & 20.42 \\
\hline 7 & 40 & 150 & 30 & 0.125 & 8.77 & 16.58 \\
\hline 8 & 40 & 180 & 25 & 0.15 & 8.62 & 17.56 \\
\hline 9 & 60 & 240 & 30 & 0.075 & 9.45 & 20.18 \\
\hline 10 & 60 & 210 & 25 & 0.1 & 10.07 & 18.91 \\
\hline 11 & 60 & 180 & 40 & 0.125 & 9.61 & 17.66 \\
\hline 12 & 60 & 150 & 35 & 0.15 & 8.76 & 16.64 \\
\hline 13 & 80 & 180 & 35 & 0.075 & 9.58 & 17.6 \\
\hline 14 & 80 & 150 & 40 & 0.1 & 9.59 & 16.54 \\
\hline 15 & 80 & 240 & 25 & 0.125 & 9.91 & 20.8 \\
\hline 16 & 80 & 210 & 30 & 0.15 & 8.72 & 19.26 \\
\hline
\end{tabular}

feeding quality, and friction coefficient are selected as controllable factors of the level table, and four levels are selected for each factor.

Level factors are input into the orthogonal Table 7, and 16 groups of process parameter combinations are generated.

Signal-to-noise ratio is the ratio between signal and noise. Types of signal-to-noise ratios are different according to various experimental optimization objectives. For hydraulic bulging process considered in this paper, numerical evaluation index is expected to be as small as possible within a reasonable range. Thus, signal-to-noise ratio $\eta$ is chosen as

$$
\eta=-10 \log _{10}\left(\frac{1}{n} \sum_{j=1}^{n} S_{j}^{2}\right) .
$$

The expected minimum value of maximum thinning ratio is set as $Y_{1}$, and SNR is set as $\eta_{1}$. The expected minimum value of maximum thickening ratio is set as $Y_{2}$, and SNR is set as $\eta_{2}$. Hence, the comprehensive SNR is

$$
\eta=\left(0.5 \eta_{1}+0.5 \eta_{2}\right)
$$

Equation (19) is used to calculate signal-to-noise ratio, and the results are shown in Table 8.

According to direct observation, the first group has the largest comprehensive signal-to-noise ratio and the best molding condition. Combination of process parameters can be obtained as $A_{1} B_{1} C_{1} D_{1}$.

Finally, SNR calculation results are analyzed: In the first step, sum of SNR is found, which is expressed as $T$ [17]. In the second step, sum and average value of SNR of each factor and each level is found. In the third step, range of each column is obtained, which is expressed as $R$. In the fourth step, sum of total fluctuation squares of SNR is acquired, which is expressed as $S_{T}$. Finally, in step five, sum of SNR square fluctuations of each factor is found, which is, respectively, expressed as $S_{1}, S_{2}, S_{3}, S_{4}$. The results are presented in Table 9.
TABLE 8: SNR calculation results table.

\begin{tabular}{lccc}
\hline Test number & $\eta_{1}$ & $\eta_{2}$ & $\eta$ \\
\hline 1 & -19.0945 & -24.3602 & -21.7273 \\
2 & -19.3450 & -24.6229 & -21.9840 \\
3 & -19.1954 & -24.9640 & -22.0797 \\
4 & -19.1704 & -25.3695 & -22.2700 \\
5 & -19.2559 & -25.3916 & -22.3237 \\
6 & -19.5082 & -25.5374 & -22.5228 \\
7 & -19.4213 & -25.3911 & -22.4062 \\
8 & -19.3385 & -25.3316 & -22.3350 \\
9 & -19.3577 & -25.4238 & -22.3908 \\
10 & -19.4334 & -25.4349 & -22.4341 \\
11 & -19.4539 & -25.3922 & -22.4231 \\
12 & -19.4067 & -25.3192 & -22.3629 \\
13 & -19.4241 & -25.2891 & -22.3566 \\
14 & -19.4396 & -25.2295 & -22.3346 \\
15 & -19.4734 & -25.3149 & -22.3942 \\
16 & -19.4348 & -25.3395 & -22.3872 \\
\hline
\end{tabular}

TABLE 9: Variance data table.

\begin{tabular}{lccccc}
\hline & $A$ & $B$ & $C$ & $D$ & \\
\hline$T_{1}$ & -88.0610 & -88.8310 & -88.8907 & -88.7984 & $T=-365.7321$ \\
$T_{2}$ & -89.5877 & -89.0986 & -89.1681 & -89.2755 & $S_{T}=0.6058$ \\
$T_{3}$ & -89.6109 & -89.2247 & -89.3220 & -89.3031 & \\
$T_{4}$ & -89.4724 & -89.5777 & -89.3513 & -89.3551 & \\
$t_{1}$ & -22.0153 & -22.2078 & -22.2227 & -22.1996 & \\
$t_{2}$ & -22.3969 & -22.2747 & -22.2920 & -22.3189 & \\
$t_{3}$ & -22.4027 & -22.3062 & -22.3305 & -22.3258 & \\
$t_{4}$ & -22.3681 & -22.3944 & -22.3378 & -22.3388 & \\
Range & 0.3875 & 0.1867 & 0.1151 & 0.1392 & \\
$(R)$ & & & & & \\
Wave & 0.4224 & 0.0721 & 0.0333 & 0.0501 & \\
$(S)$ & & & & & \\
\hline
\end{tabular}

In the sixth step, variance is analyzed. The results are presented in Table 10. 
TABLE 10: Variance analysis table.

\begin{tabular}{lccccc}
\hline Source & $S$ & $f$ & $V$ & $F$ value & $R$ square \\
\hline$A$ & 0.4224 & 3 & 0.1408 & 12.6737 & 2.1641 \\
$B$ & 0.0721 & 3 & 0.0240 & 0.1502 \\
$C$ & 0.0333 & 3 & & 1.5042 \\
$D$ & 0.0501 & 3 & 0.0167 & 0.0132 \\
$(e)$ & $(0.0333)$ & 3 & 0.0111 & 0.0194 \\
$T$ & 0.583 & & & \\
\hline
\end{tabular}

TABLE 11: SNR response table.

\begin{tabular}{lccr}
\hline Level & & Factor & \\
& Molding pressure $(\mathrm{MPa})$ & Feeding quantity $(\mathrm{mm})$ & Friction coefficient \\
\hline 1 & -100.3000 & -100.4416 & -100.4646 \\
2 & -100.6358 & -100.7773 & -100.8248 \\
3 & -101.1300 & -101.1097 & -101.0622 \\
4 & -102.6957 & -101.3828 & -101.3598 \\
\hline
\end{tabular}

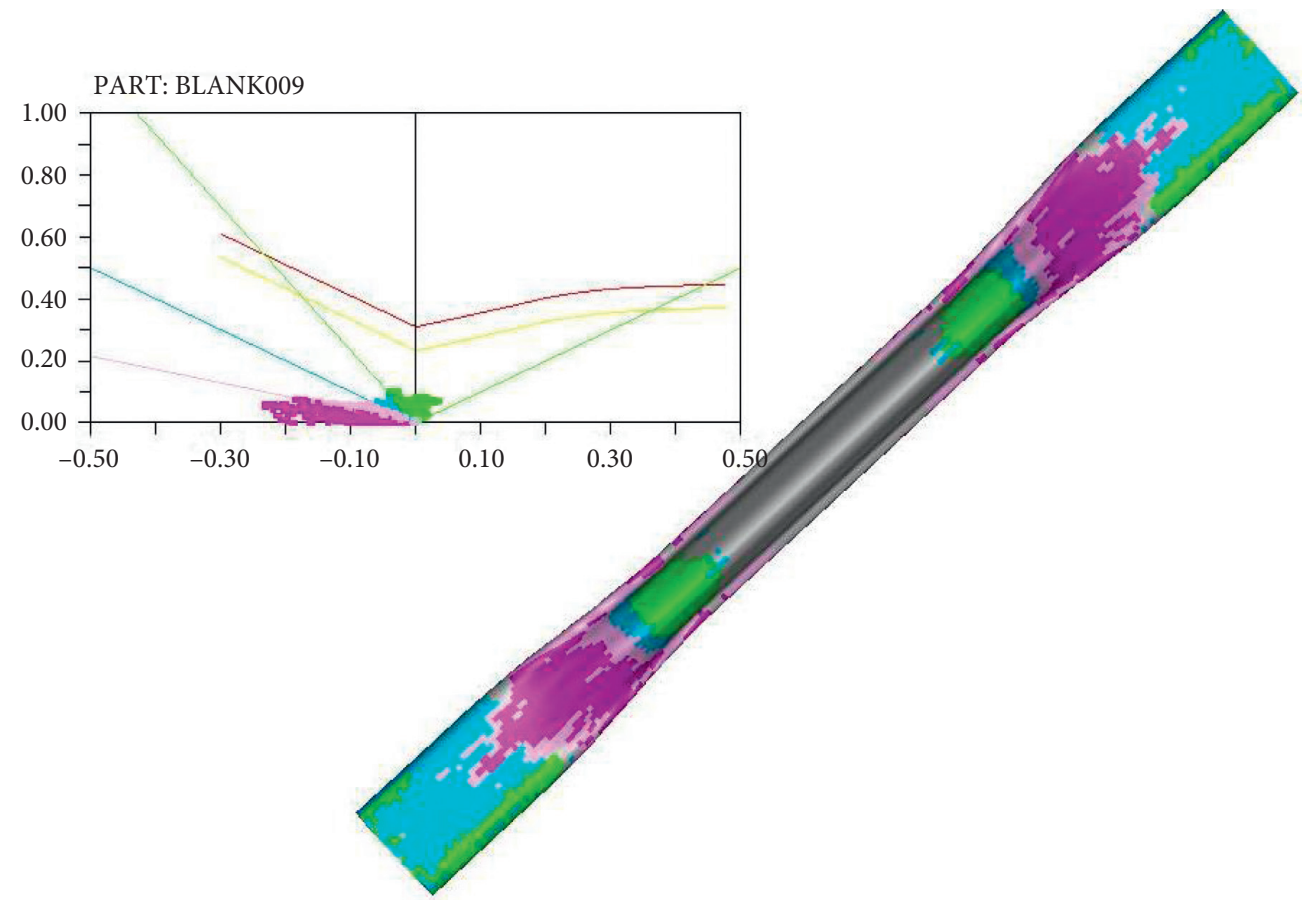

Figure 20: FLD of $A_{1} B_{1} C_{1} D_{1}$ combination.

Based on SNR variance analysis ratio, factor $A$ has a significant impact on quality fluctuation characteristics. Factor $A$ is considered a stable factor, while factors $B, C$, and $D$ are adjustable factors. For stable factors, the level is $A_{1}$. SNR values of maximum thickening ratio fraction of factors $B, C$, and $D$ are listed in Table 11 .

As factors $B, C$, and $D$ have minor influence on quality fluctuation characteristics, maximum thinning rate can be neglected, and parameters $B, C$, and $D$ can be simply adjusted to minimize the maximum thickening rate. According to Table 11, optimal process parameter is $B_{1} C_{1} D_{1}$ when only maximum thickening rate is considered.

As shown in Figures 20 and 21, final optimized combination is $A_{1} B_{1} C_{1} D_{1}$, maximum thinning rate is $9.013 \%$, and maximum thickening rate is $16.523 \%$. These results are basically consistent with the optimized combination $A_{1} B_{1} C_{1} D_{1}$ obtained via intuitive method. 

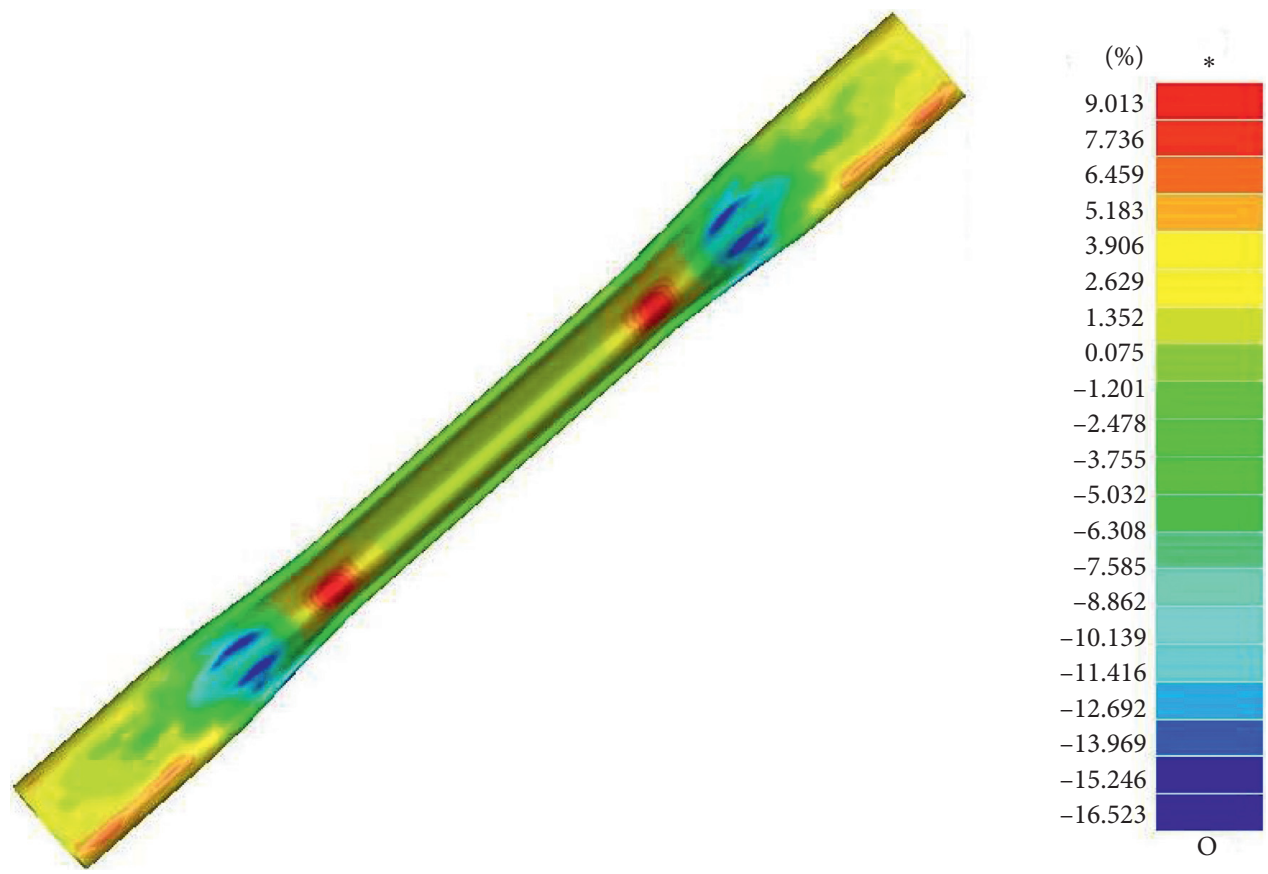

Figure 21: Nephogram of thinning rate of $A_{1} B_{1} C_{1} D_{1}$ combination.

\section{Conclusions}

(1) CATIA is used to design three-dimensional modeling of tubular torsion beam, and corresponding materials and initial tube blank are selected for the processed products. The forming process of parts is determined, and calculation of relevant process parameters in hydraulic bulging is completed.

(2) CATIA is used to design hydraulic bulging torsion beam die. In addition, hydraulic synchronous control system, which can automatically correct deviation, is designed for synchronous cylinders on both sides of the die. Synchronous displacement curves of two cylinder piston rods under two different working conditions are obtained in AMESim. When the same load pressure is applied to both hydraulic cylinders, displacement curves of cylinder piston rods are completely coincident, and the corresponding displacement error is $0 \mathrm{~mm}$. The moving valve core is in the middle position. When different load pressures are applied to cylinders, the servo valve can adjust the flow at the diversion port based on valve core displacement. Therefore, displacement of two piston rods is kept consistent. Hence, automatic deviation correction function of hydraulic control system is successfully verified. Mathematical model of hydraulic control system is established, and system synchronization is verified via Simulink.

(3) Maximum thinning rate and maximum thickening rate are taken as forming evaluation indexes. Simulation analysis of torque beam hydraulic bulging process was completed via DYNAFORM. Maximum thinning rate and maximum thickening rate of preformed parts were $7.889 \%$ and $16.188 \%$, respectively. No wrinkle or flash defects were observed. After hydraulic bulging, maximum thinning rate and maximum thickening rate of parts were $9.577 \%$ and $17.574 \%$, respectively, which were in the qualified range. The forming parts were divided into four regions, $A, B, C$, and $D$. Wall thickness variation of each region was analyzed.

(4) Process parameters of hydraulic bulging torsion beam were optimized by employing Taguchi algorithm, and accuracy of optimization results was verified via DYNAFORM. Optimal molding parameters are as follows: supporting pressure is $20 \mathrm{MPa}$, molding pressure is $150 \mathrm{MPa}$, feeding quantity is $25 \mathrm{~mm}$, friction coefficient is 0.075 , maximum thinning rate is $9.013 \%$, and maximum thickening rate is $16.523 \%$ [18-26].

\section{Data Availability}

The data used to support the findings of this study are included within the article.

\section{Conflicts of Interest}

The authors declare that they have no conflicts of interest.

\section{Acknowledgments}

This article belongs to the major projects of the University Synergy Innovation Program of Anhui Province (GXXT2019-004) and the project of the Teaching Research Project of Anhui Education Department (2019jyxm0229). 


\section{References}

[1] E. Liu, Fea of Stress and Deflection in Dies of Tube Hydroforming, Harbin Institute of Technology, Harbin, China, 2006.

[2] X. Yin and R. Lu, "Finite element simulation and experiment on hydroforming tubular twist beam," Forging and Stamping Technology, vol. 42, no. 9, pp. 82-86, 2017.

[3] R. Lu, X. Chen, and X. Hu, "Study on tube hydorforming torsion beam design based on topological analysis," Automobile Applied Technology, vol. 45, no. 3, 59 pages, 2020.

[4] M. Mirzaali, S. M. H. Seyedkashi, G. H. Liaghat, H. Moslemi Naeini, G. K. Shojaee, and Y. H. Moon, "Application of simulated annealing method to pressure and force loading optimization in tube hydroforming process," International Journal of Mechanical Sciences, vol. 55, no. 1, pp. 78-84, 2012.

[5] P. Venkateshwar Reddy, B. Veerabhadra Reddy, and P. Srinivasa Rao, "A numerical study on tube hydroforming process to optimize the process parameters by Taguchi method," Materials Today: Proceedings, vol. 5, no. 11, pp. 25376-25381, 2018.

[6] V. Dhinakaran, A. R. Kumar, R. Ramgopal, S. Kannan, B. Stalin, and T. Jagadeesha, "Topology optimization of steering knuckle," in Advances in Industrial Automation and Smart Manufacturing. Lecture Notes in Mechanical Engineering, A. Arockiarajan, M. Duraiselvam, and R. Raju, Eds., Springer, Singapore, pp. 197-206, 2021.

[7] P. Xie, Injection Mold Design of Automobile Dash Panel Decorative Panel and Optimization of its Process Parameters, Anhui Polytechnic University, Wuhu, China, 2019.

[8] L. Yang, Research and Development of Internal High Pressure Hot Forming Equipment and Forming Technology, Nanjing University of Science and Technology, Nanjing, China, 2017.

[9] Yu. Meng, Study on Influence of Pulsating Loading on Tube Formability in Hydroforming and its Mechanism, Northeastern University, Boston, MA, USA, 2010.

[10] X. Lin, Research and Design of Advanced High-Pressure Tube Hydroforming System with the Function of Pulsating Loading, Northeastern University, Boston, MA, USA, 2011.

[11] P. Wan, Simulation of Forming Process and Optimization of Forming Process Parameters of Automobile Fender Based on Taguchi Algorithm, Anhui Polytechnic University, Wuhu, China, 2017.

[12] S. Yuan, Modern Hydroforming Technology (fine), National Defense Industry Press, Arlington, VA, USA, 2009.

[13] Y. Jin, Study on Simulation of Bulging-Pressing Torsion Beam, Yanshan University, Qinhuangdao, China, 2016.

[14] J. Sun, Parameter Optimization and Performance Prediction Research on Desulfurization Dust Removal Pump, Anhui Polytechnic University, Wuhu, China, 2014.

[15] J. Zheng, A. Cheng, L. Dong, and P. Lei, "The application of taguchi robust design to vehicle crashworthiness optimization," Automotive Engineering, vol. 33, no. 9, pp. 772-776, 2011.

[16] Y. Tan, Optimization Research of Plastic Centrifugal Pump Cavitation Performace Based on Cfd Flow Field, Anhui Polytechnic University, Wuhu, China, 2015.

[17] B. Hu, Q. Zhang, X. Zhao, and J. Dong, "Research on optimization design of CRT thermal explosion cutting equipment based on taguchi method," Machinery Design and Manufacture, no. 5, pp. 15-17, 2010.

[18] C. Nikhare, M. Weiss, and P. D. Hodgson, "Buckling in low pressure tube hydroforming," Journal of Manufacturing Processes, vol. 28, pp. 1-10, 2017.
[19] A. Fethi, A. Furqan, G. Sana, B. Touhami, K. Ali, and S. C. Heung, "Design of T-shaped tube hydroforming using finite element and artificial neural network modeling," Journal of Mechanical Science and Technology, vol. 34, no. 1, 2020.

[20] M. Mehran, S. K. Javad, and J. H. Seyed, "Forming limit diagram of aluminum/copper bi-layered tubes by bulge test," The International Journal of Advanced Manufacturing Technology, vol. 92, no. 5-8, pp. 1539-1549, 2017.

[21] S. Haidi, L. Jian, R. Jili, and X. Gao, "Analysis of tubes with rectangular section forming process by fluid-solid coupling method," The International Journal of Advanced Manufacturing Technology, vol. 102, no. 5-8, pp. 2491-2509, 2019.

[22] H. Minsu, Y. Jaemin, L. Jaejun, and H. Seung-Jin, "Development of coupled torsion beam axle dynamic model based on beam elements," International Journal of Precision Engineering and Manufacturing, vol. 22, no. 1, pp. 1-15, 2020.

[23] Y. Kai, X. Fei, L. Kai, and H. Cheng, "Research on torsion beam with high strength steel materials forming," Key Engineering Materials, vol. 4332, pp. 136-141, 2017.

[24] A. Ramaswamy, A. V. Perumal, J. Jagadeesan, and P. Kaladharan, "Optimization of WEDM process parameters for D3 die steel using RSM," vol. 37, no. 1, https://www. researchgate.net/journal/Materials-Today-Proceedings-22147853, 2020.

[25] Z. Chen, F. Yu, W. Han, and H. Hai, "Multi-objective optimization of process parameters during low-pressure die casting of AZ91D magnesium alloy wheel castings," China Foundry, vol. 15, no. 5, pp. 327-332, 2018.

[26] S. Samaneh, H. Mohammad, H. Ghassem, and P. Hadi, "Multi-objective optimization of underfloor air distribution (UFAD) systems performance in a densely occupied environment: a combination of numerical simulation and Taguchi algorithm," vol. 32, 2020 https://www.researchgate.net/ journal/Journal-of-Building-Engineering-2352-7102, Article ID 101495. 